\author{
Universidade de São Paulo \\ Escola de Engenharia de São Carlos \\ Departamento de Engenharia Elétrica
}

\title{
Estimação do fluxo multidirecional de pedestres em ambientes abertos e não restritos, pela análise de seqüências de imagens digitais.
}

\author{
Paulo Henrique Gonçalves
}

Orientadora: Profa. Dra. Maria Stela Veludo de Paiva

Dissertação de mestrado apresentada à Escola de Engenharia de São Carlos USP, como parte dos requisitos para obtenção do título de Mestre em Engenharia Elétrica. 
Ao meu pai, Manoel, e à minha mãe, Nair. 


\section{Agradecimentos}

Ao nosso Deus, até a Quem as ondas dos mares e seus ventos obedecem.

À Santa Rita de Cássia, pela eterna e poderosa interceção.

Aos meus pais, pelas horas de orações.

À Profa. Dra. Maria Stela, pela paciência, atenção e por ter acreditado em $\operatorname{mim}$.

Ao Prof. Dr. Valentin Obac Roda, pela sua colaboração no processo de qualificação.

À amiga Jackeline, por ter me mostrado o LaTex.

À amiga Cristiane e ao Danival, pela enorme apoio incondicional.

Ao amigo Fernando Salina, pelos cafés em São Carlos.

À amiga Maria Érica, por ter dado apoio com o texto da qualificação.

Aos amigos Paulo Rotta e Ana Lúcia, pela amizade e paciência.

À amiga Cláudia Milaré pela força dada nos momentos difíceis.

Ao amigo Geraldo, pela revisão do texto e por morar em Curitiba.

Ao Dr. Lofrano, por ter me ajudado a ver que sou mais capaz do que acreditava.

Às secretárias da SEL, Denise e Marisa, pela atenção. 


\section{Resumo}

O problema de contagem de pessoas em uma determinada região é de grande importância, e tem várias aplicações, tais como: planejamento dos serviços fornecidos por cinemas, shoppings centers, companhias de ônibus, assim como para o monitoramento do tráfego de pedestres em áreas urbanas.

A necessidade de se conceber sistemas confiáveis capazes de contabilizar, em tempo real, o número de pessoas circulando em uma determinada região tem sido evidenciado por essas aplicações.

Este trabalho apresenta um sistema de baixo custo para a estimação do fluxo multidirecional de pedestres, em ambientes abertos e não restritos, baseado na seqüência de imagens digitais, capturadas por uma única câmera vídeo tipo WEBCAM. A câmera é colocada na vertical do espaço a ser monitorado, e conectada a um PC através da porta USB. A metodologia tem como base o trabalho desenvolvido por Pádua (2002) e utiliza o algoritmo proposto em Lucas e Kanade (1981) que computa o fluxo óptico das imagens capturadas pela câmera. Uma análise espaço-temporal desse fluxo é realizada para determinar o fluxo multidirecional dos pedestres.

PALAVRAS-CHAVE: contagem de pedestres, fluxo óptico, câmera digital de vídeo. 


\begin{abstract}
The problem in counting people in restricted area is of great importance in planning the services offered by cinemas, malls and bus companies and also for controlling pedestrians traffic in urban areas.

These applications has evinced the need for developing reliable real time systems capable of counting pedestrians in regions of interest.

This work presents a low cost system for estimating the multidirectional flow of pedestrians in open areas and non-restricted areas. This system has only one WEBCAM placed in a vertical position in the area to be monitored. This camera is connected to the PC computer system through the USB port. The methodology is based in the work developed by Pádua (2002) and in the algorithm proposed by Lucas e Kanade (1981) that computerizes the optical flow of the images acquired by the stationary camera. The multidirectional flow is estimated by the temporal-space analysis of this optical flow.
\end{abstract}

KEYWORDS: pedestrians counting, optical flow, digital video camera. 


\section{Lista de Figuras}

2.1 Classes de sistemas para contagem automática de pedestres. . . . . . 4

3.1 Definição do conceito de sinal de vídeo digital (Roma, 2001). . . . . . 14

3.2 Problema de oclusão (Tekalp, 1995). . . . . . . . . . . . . . . . . 16

3.3 Problema de abertura $($ Nesi, 1994). . . . . . . . . . . . . . . 16

3.4 Métodos para estimação do fluxo óptico encontradas na literatura pesquisada. . . . . . . . . . . . . . . . . . . . 18

3.5 Linha da restrição e componente normal do fluxo óptico. . . . . . . . 19

3.6 Vizinhança $\Omega$ de $N \mathrm{x} N$ pixels. . . . . . . . . . . . . . . 23

3.7 Correspondência entre blocos (Kuzina, 2000). . . . . . . . . . . . . . 25

3.8 Visão do topo de uma pessoa em pé e as dimensões entre ombros, $Y_{o}$, e da profundidade do tórax, $Y_{p}$, que serão utilizados neste trabalho. $\quad 29$

4.1 Visão geral do sistema proposto. . . . . . . . . . . . . . . . . . . . 33

4.2 Posição da câmera de vídeo em relação ao chão. . . . . . . . . . . . . . 34

4.3 Fluxo multidirecional de pedestres: o pedestre rotulado pelo número 1 entra na região monitorada pela área 1 e pode sair por qualquer outra área. . . . . . . . . . . . . . . . . . . . . . . . 35

4.4 Divisão e sub-divisão da região monitorada pela câmera de vídeo. . 35

4.5 (a) Imagens capturadas com período igual a $T A$.(b) e (c) Imagens capturadas com períodos inferiores a $T A \ldots$. . . . . . . . . 37

4.6 Único pedestre cruzando a sub-área 3-2 em dois instantes de tempo: (a) $t-\delta t$ e (b) $t$; e (c) vetores $v$ do campo de fluxo óptico gerados no instante $t$ devido ao movimento deste pedestre, bem como suas componente ortogonais $u$ e $r$. . . . . . . . . . . . . . . . . 38 
4.7 Somatório da componente $|r|$ do vetor velocidade $v$ na sub-área 3-2, em todas as colunas. . . . . . . . . . . . . . . . . . 39

4.8 (a) Gráfico do somatório da componente $|r|$ do vetor velocidade $v$ na sub-área 3-2 no instante $t$ e os limiares Tmax e Tmin. (b) Pulso $P_{32}$ gerado na sub-área 3-2, devido à presença de um objeto em movimento nessa sub-área no instante $t$. . . . . . . . . . . . . . . . . . . . 40

4.9 Pulso $P$ gerado por um objeto em movimento na sub-área 3-2, com largura $b$ e ponto médio $P m \ldots$. . . . . . . . . . . . . . . . 40

4.10 Três pedestres cruzando a área 3 nos instantes de tempo (a) $t_{0}$, (b) $t_{1}$, (c) $t_{2}$ e (d) $t_{3}$, sendo $t_{3}>t_{2}>t_{1}>t_{0}$, com pedestres 1 e 2 caminhando no sentido positivo do eixo $y$ e o pedestre 3 no sentido negativo de $y$, e os respectivos pulsos $P_{31}$ e $P_{32}$ gerados pelo movimento desses pedestres nas sub-áreas 3-1 e 3-2, para um período de amostragem TA 42

4.11 (a) Pulso no instante $t$ com largura $b_{1}$ e o ponto médio $P m_{1}$, na suaárea 3-2. (b) Pulso no instante $t-\delta t$ com largura $b_{0}$ e o ponto médio $P m_{0}$, na sub-área 3-1.

4.12 Calibração do sistema: um objeto de calibração de 1,0 metro, para a câmera de vídeo colocada a 7,6m, tem um comprimento de 60 pixels.

4.13 Projeção perspectiva das dimensões corporais $Y_{o}$ e $Y_{p}$ e de suas respectivas projeções no plano de imagem, $y_{o}$ e $y_{p} \ldots \ldots . . . . .445$

5.1 Câmera de vídeo digital Panasonic, modelo miniDV PV-GS12. . . . . 47

5.2 Câmera de vídeo digital Aiptek, modelo DV 3100. . . . . . . . . . . . 47

5.3 Posição da câmera vista por dois ângulos diferentes. . . . . . . . . . . . 47

5.4 Região monitorada pela câmera. . . . . . . . . . . . . . . . . . . . . . 48

5.5 Seqüência de imagens 1 - pedestres caminham predominantemente nas direções $x$ ou $y \ldots \ldots \ldots$. . . . . . . . . . . . . . . . . . . . . . . . . 48

5.6 Seqüência de imagens 2 - pedestres caminham predominantemente nas direções dos eixos $x$ ou $y$, lado-a-lado, aos pares. . . . . . . . . . . 48

5.7 Seqüência de imagens 3 - pedestres caminham predominantemente em direções diagonais.

5.8 Pedestre saindo da região monitorada pela área 2. As linhas pretas verticais indicam os limites das sub-áreas $2-1$ e 2-2. . . . . . . . . . . 52

5.9 Mesmo pedestre visto na Figura 5.8, instantes antes, caminhando na região central. . . . . . . . . . . . . . . . . . . 52 
5.10 Pedestre caminhando da área 1 em direção a área 2, sobre a área 4. 52

5.11 Pedestre saindo da região monitorada pela câmera de vídeo pela intersecção da área 1 e 4 . . . . . . . . . . . . . . . . . . . . . 52

6.1 Posições sugeridas para as áreas utilizadas para contagem e estimação da direção dos pedestres. . . . . . . . . . . . . . . . . . . . 55 


\section{Lista de Tabelas}

3.1 Comparação entre métodos para estimação do fluxo óptico. . . . . . . 28

3.2 Larguras entre ombros sugeridas em Diffrient et al. (1981). . . . . . . 29

5.1 Resultados nas quatro seqüências obtidas pela câmera Panasonic. . . 49

5.2 Resultados nas quatro seqüências obtidas pela câmera Aiptek. . . . . 49

5.3 Resultados globais para as duas câmeras. . . . . . . . . . . . . . 50 


\section{Sumário}

Dedicatória ................................ ii

Agradecimentos .......................... ii

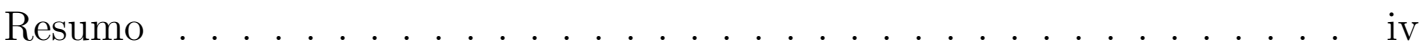

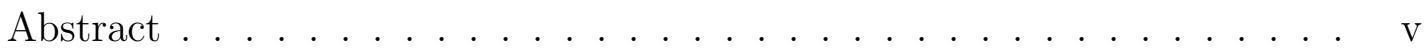

Lista de Figuras . . . . . . . . . . . . . . . . . . . . . vi

Lista de Tabelas . . . . . . . . . . . . . . . . . . . ix

Sumário ......................... . . $\mathrm{x}$

1 Introdução 1

1.1 Motivação . . . . . . . . . . . . . . . . . . 1

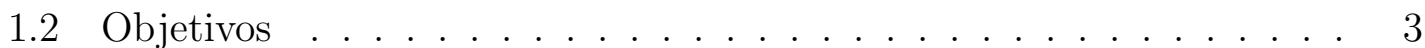

1.3 Organização do trabalho . . . . . . . . . . . . . . . . . 3

2 Sistemas para a contagem automática de pedestres $\quad 4$

2.1 Considerações iniciais . . . . . . . . . . . . . . . . . . . . . . . . . . 4

2.2 Sistemas com sensores . . . . . . . . . . . . . . . . . . 4

2.3 Sistemas com câmeras de vídeo . . . . . . . . . . . . . . . . . 6

2.4 Considerações finais . . . . . . . . . . . . . . . . . . . . . . . . 11

3 Fundamentos teóricos de sistemas para contagem de pedestres $\quad 13$

3.1 Considerações iniciais . . . . . . . . . . . . . . . . . . . . . 13

3.2 Estimação de movimento em seqüências de imagens digitais . . . . . . 13

3.3 Métodos para a estimação do fluxo óptico . . . . . . . . . . . . . . 17

3.3.1 Métodos baseados em gradiente . . . . . . . . . . . . 18

3.3.1.1 Métodos baseados em regularização . . . . . . . . . 20 
3.3.1.2 Métodos baseados em multi-restrição . . . . . . . . . 21

3.3.2 Método baseado em correspondência . . . . . . . . . . . 24

3.3.3 Métodos baseados em filtros . . . . . . . . . . . . 25

3.4 Estudos comparativos entre os métodos para estimação do fluxo óptico 26

3.5 Características físicas de pedestres . . . . . . . . . . . . . 27

3.5.1 Dimensões humanas . . . . . . . . . . . . . . . . . 28

3.5.2 Velocidade de pedestres . . . . . . . . . . . . . . . 29

3.6 Considerações finais . . . . . . . . . . . . . . . . . . . 30

4 Descrição do sistema para a contagem de pedestres em fluxo multidirecional.

4.1 Considerações iniciais . . . . . . . . . . . . . . . . . . . . . . 32

4.2 Visão geral do sistema proposto . . . . . . . . . . . . . . . . . 32

4.3 Captura da seqüência de imagens digitais . . . . . . . . . . . . . 33

4.4 Estimação do fluxo multidirecional . . . . . . . . . . . . . . . . 34

4.4.1 Somatório das componentes ortogonais dos vetores velocidade 37

4.4.2 Segmentação dos objetos que se movem pela cena . . . . . . . 39

4.4.3 Validação, contagem e estimação da direção dos pedestres na região monitorada . . . . . . . . . . . . . . . . . . . 41

4.5 Calibração do sistema . . . . . . . . . . . . . . . . . 42

4.6 Considerações finais . . . . . . . . . . . . . . . . . . . . . . . 45

5 Aquisição, processamento dos dados e análise dos resultados $\quad 46$

5.1 Considerações iniciais . . . . . . . . . . . . . . . . . . . . . 46

5.2 Aquisição das seqüências de imagens . . . . . . . . . . . . . . 46

5.3 Resultados obtidos . . . . . . . . . . . . . . . . . . . 49

5.4 Análise dos resultados obtidos . . . . . . . . . . . . . . . . 50

6 Conclusões e sugestões para trabalhos futuros 53

6.1 Conclusões . . . . . . . . . . . . . . . . . . . . . 53

6.1.1 Principais contribuições . . . . . . . . . . . . 54

6.1 .2 Limitações . . . . . . . . . . . . . . . . . . . . . . 54 
6.2 Sugestões para trabalhos futuros . . . . . . . . . . . . . . . . . 54

$\begin{array}{ll}\text { Referências bibliográficas } & 56\end{array}$ 


\section{Capítulo 1}

\section{Introdução}

\subsection{Motivação}

A estimação do fluxo de pedestres em uma determinada região pode ser útil em muitos contextos: em estabelecimentos comerciais, para estimar o fluxo de clientes que entram e saem destes, ou mesmo, que circulam pelo interior dos mesmos, podendo fornecer uma importante informação para o planejamento dos serviços prestados. Pode ser muito útil também em museus, teatros, cinemas e aeroportos.

Em centros de compras, como shopping centers, a avaliação do tráfego de pessoas é relevante para os administradores, bem como para os lojistas. Nesses estabelecimentos não só a informação do número de clientes é importante, como também o número de pessoas que trafegam em cada um de seus corredores e quais direções preferencialmente tomam, permitindo, dessa forma, determinar quais são as zonas de menor fluxo. Essas informações podem ser usadas, por exemplo, no desenvolvimento de estratégias para aumentar o fluxo de pessoas nas regiões de menor fluxo.

Estimar o fluxo de pedestres, bem como suas direções, tem aplicação também nos modernos sistemas de monitoração de tráfego urbano para o melhor planejamento de espaços e serviços urbanos (Pádua et al., 2003).

$\mathrm{Na}$ literatura encontram-se outras aplicações desses sistemas em diferentes situações, citando-se, por exemplo: sistema para contagem de pessoas à espera de um elevador, para melhorar a eficiência deste serviço (Schofield et al., 1997); sistema automático de contagem de pedestres que passam por uma porta de segurança na entrada de um edifício (Kim et al., 2002); sistema automático para contagem do número de usuários que entram e saem de um ônibus (Bartolini et al., 1994); sistema para estimar o número de usuários que utilizam um serviço de trem através do seu 
fluxo na plataforma (Sexton et al., 1995); em (Masoud e Papanikolopoulos, 2001) é descrito um sistema para a estimação do fluxo de pedestres em um cruzamento em espaço urbano.

Sistemas mecânicos, como catracas e portas giratórias, ou, que utilizam sensores, como placas sensíveis a peso e células fotoelétricas, têm sido freqüentemente usados como soluções técnicas para o problema de contagem de pessoas. Esses sistemas não são apropriados a situações em que o fluxo de pedestres não é regular, ou quando as pessoas caminham muito próximas uma das outras. Além disso, podem impedir o rápido deslocamento das pessoas em casos de emergência. Outro problema relacionado com essas soluções é que normalmente requerem uma infraestrutura, onde os sensores possam ser alojados, o que dificulta o seu uso em espaços não restritos tais como, calçadas, corredores e entrada de estabelecimentos comerciais (Pádua, 2002).

O desenvolvimento de sistemas automáticos para contar pedestres, baseado em técnicas de processamento de seqüência de imagens digitais, tem despertado considerável interesse de pesquisadores nesta área (Sacchi et al., 2000) o que pode ser comprovado pelo número de pesquisas relacionado ao tema. Neste contexto, sistemas utilizando câmeras de vídeo surgiram como boa alternativa para a estimação do fluxo de pedestres, já que necessitam de pouca infra-estrutura, e, os atuais processadores podem possibilitar o desenvolvimento de sistemas de baixo custo e em tempo real (Beymer, 2000; Kim et al., 2002) .

Um sistema automático para a contagem de pedestres, utilizando câmeras de vídeo, deve ser capaz de lidar com diversos problemas, tais como: vibrações mecânicas, flutuações de luminosidade, variações ambientais e fluxo irregular de pedestres. Como tarefas a serem realizadas por esses tipos de sistemas pode-se enumerar: a detecção de movimento das pessoas presentes na cena, a segmentação das mesmas e a estimação da direção delas.

Quanto a aplicabilidade distinguem-se dois tipos de sistemas: sistemas para medir fluxo unidirecional, com aplicação, por exemplo, em corredores estreitos de ambientes fechados, onde este tipo de fluxo é mais comum; e sistemas para medir fluxo multidirecional, onde pedestres podem ter direções diferentes, como é o caso de pedestres caminhando em ambientes não restritos, como calçadas, praças e corredores largos de estabelecimentos comerciais.

O Capitulo 2 apresenta diversos trabalhos para a estimação do fluxo unidirecional. Já para do fluxo multidirecional, que é uma caso mais complexo do fluxo de pedestres, foi encontrada na bibliografia somente uma proposta de metodologia (Pádua et al., 2003). Este trabalho baseou-se nessa metodologia proposta para estimar 
o fluxo multidirecional de pedestres.

\subsection{Objetivos}

O objetivo desse trabalho é implementar um algoritmo para estimar o fluxo multidirecional de pedestres, em ambientes abertos e não restritos, através da análise de seqüências de imagens digitais. As imagens são capturadas por uma única câmera de vídeo, do tipo WEBCAM, colocada na vertical, sobre a região monitorada e processadas por um computador do tipo PC. A câmera de vídeo foi ligada ao PC através da porta USB. O sistema final apresenta também as seguintes características:

- robustez quanto à variação de iluminação e vento;

- robustez quanto à distinção de pessoas que caminham muito próximas, ladoa-lado;

- baixo custo computacional;

- baixo custo financeiro.

\subsection{Organização do trabalho}

Este trabalho é constituído por seis capítulos:

- no primeiro capítulo foi realizada a introdução ao assunto, destacando sua aplicabilidade e importância, e apresentando o objetivo dessa pesquisa;

- no Capítulo 2 são apresentados os principais trabalhos encontrados na literatura relacionados com a contagem automática de pedestres;

- no Capítulo 3 são apresentados alguns métodos para a estimação do fluxo óptico em seqüências de imagens digitais e também características físicas de pedestres relevantes para este trabalho;

- no Capítulo 4 é apresentada a metodologia utilizada;

- o Capítulo 5 descreve a aquisição e processamento dos dados, apresentando também a análise dos resultados obtidos;

- no Capítulo 6 são apresentadas as conclusões, as principais contribuições deste trabalho, suas limitações e sugestões para trabalhos futuros. 


\section{Capítulo 2}

\section{Sistemas para a contagem automática de pedestres}

\subsection{Considerações iniciais}

Neste capítulo são descritos os principais trabalhos da literatura pesquisada, para a contagem automática de pedestres utilizando sensores e câmeras de vídeos.

Para uma melhor organização da descrição desses trabalhos, eles são agrupados em duas classes de acordo com o sensor utilizado para a detecção dos pedestres conforme mostra a Figura 2.1.

\subsection{Sistemas com sensores}

Os trabalhos pertencentes a Classe 1 apresentam soluções para a contagem de pedestres baseadas principalmente em sensores para detectar a presença de pessoas que caminham em uma região monitorada por esses.

Sistemas baseados em sensores fotoelétricos podem ser constituídos por um ou

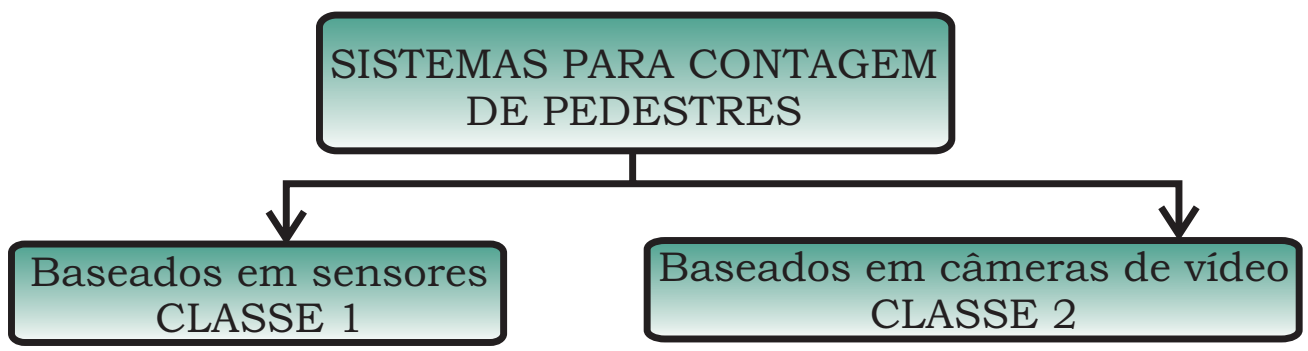

Figura 2.1: Classes de sistemas para contagem automática de pedestres. 
mais pares de emissores-receptores de luz. A contagem de pedestres é obtida através da interrupção no receptor, do feixe emitido pelo emissor. Esses sistemas necessitam de uma infra-estrutura onde os sensores possam ser alojados, o que dificulta sua utilização em espaços abertos ou amplos, tais como calçadas em espaços urbanos, ou corredores largos em ambientes fechados. Outro problema relacionado a esses sistemas é que o feixe de luz pode ser interrompido ao mesmo tempo por duas pessoas, o que causaria um erro de contagem, já que elas seriam contabilizadas apenas como uma. Isso dificulta sua utilização em espaços onde o fluxo de pedestres é grande. Outra restrição desses sistemas está relacionada com a impossibilidade de se distinguir uma pessoa de um outro objeto qualquer que se move dentro do espaço monitorado. Sistemas desse tipo são apresentados em Fitter (1994), Watkins (2001) e Hsieh et al. (2002).

Outro tipo de sensor utilizado em sistemas para contagem de pedestres é o sensor de pressão. Esses sistemas trabalham como placas sensíveis à pressão que são alojadas no piso da área onde os pedestres passarão. A instalação de uma infra-estrutura física, na região onde as pessoas caminham, se faz necessária, o que restringe a sua utilização a áreas limitadas. Apresentam também problemas na distinção de duas ou mais pessoas que caminham muito próximas, já que o mesmo sensor pode ser ativado simultaneamente por indivíduos diferentes. Os trabalhos de Goren e Garti (1997) e Beezley (1999) utilizam esse tipo de sensor.

Em Hashimoto et al. (2000) é apresentado um sensor cerâmico piroelétrico, infravermelho de alto desempenho para detecção de pessoas. Sensores piroelétricos são constituídos de um material piroelétrico que é isolante com propriedades térmicas e elétricas, sendo que o material mais comum para sensores piroelétricos é o trissulfeto de glicina. O efeito piroelétrico depende mais do índice de mudança de temperatura do sensor do que da temperatura em si. Um módulo composto de uma matriz unidimensional de oito elementos com esse sensor, em conjunto com uma lente esférica infravermelha e de um sistema mecânico móvel, foi utilizado na detecção de pedestres nos trabalhos apresentados em Hashimoto et al. (1997) e Hashimoto et al. (1998) e conseguiu 99\% de acertos na contagem dos pedestres e $95 \%$ na estimação de sua direção. O sistema, apesar dos bons resultados apresentados, tem sua utilização limitada a ambientes fechados.

Em Shapira (1997) e Garcia et al. (2000) é utilizado um arranjo bidimensional de células independentes, sensíveis à pressão. Através desse arranjo são obtidas imagens digitais das pegadas inteiras ou parciais, das pessoas que caminham sobre essa superfície. Por análise temporal dessas imagens, o número de pessoas, bem como suas direções, são estimados. Novamente, essas soluções não são adequadas para ambientes abertos devido à infra-estrutura que precisa ser instalada. Além 
disso, essa abordagem tem que tratar de problemas como: a definição da resolução do arranjo de sensores, as variações na forma das pegadas, os tamanhos de pés, o peso da pessoa e até mesmo a velocidade delas. Todos esses fatores contribuem para aumentar a complexidade computacional de tais soluções.

Em Kato (1999) emprega-se um sensor de temperatura junto com câmeras infravermelhas. Nesse caso, o sensor é usado para definir um limiar que é utilizado para segmentar as pessoas nas imagens. Essa metodologia não é apropriada para ambientes cujas temperaturas variam significativamente, como normalmente acontece em cenas ao ar livre. Além disso, não é proposto nenhum método para determinar a direção do movimento das pessoas, já que seu uso está focalizado na contagem de pessoas paradas que esperam por um serviço em lugar fechado, tal como o de um elevador.

\subsection{Sistemas com câmeras de vídeo}

As soluções que se enquadram na Classe 2 representam uma tendência mais recente no desenvolvimento da tecnologia para estimar fluxos de pedestres. Sistemas dessa classe são constituídos por uma ou mais câmeras de vídeo e por uma unidade de hardware que executa os algoritmos responsáveis para a interpretação da seqüência de imagens digitais. A análise baseia-se exclusivamente nessa seqüência.

Um dos primeiros trabalhos desenvolvidos, relacionados à Classe 2, é apresentado em Bartolini et al. (1994), onde é utilizado um sistema para contabilizar o número de usuários que entram e saem de um ônibus. O sistema proposto alterna entre dois estados: a detecção do alvo e a validação do mesmo com a estimação de sua direção. No primeiro estado, detecção do alvo, a cena é continuamente verificada para se detectar possíveis mudanças induzidas pelo movimento de um objeto. Quando o sistema muda para o segundo estado, ele começa a avaliar a direção do movimento utilizando-se de um algoritmo para a estimação do fluxo óptico. A presença de um objeto real de estudo, no caso, uma pessoa em movimento, é validada através da análise das seções transversais das partes que estão se movendo. O sistema apresentou um acerto de $98 \%$ na estimação do fluxo de usuários que entram e saem de um ônibus.

Outro trabalho relevante encontrado na literatura, conhecido por ESPRIT PEDMON $^{1}$, e descrito em Sexton et al. (1995), foi patrocinado pelo órgão europeu $\mathrm{CEC}^{2}$. O objetivo desse projeto foi desenvolver um sistema para contagem automática de pedestres em áreas não limitadas e tornar disponível tal informação

\footnotetext{
${ }^{1}$ PEDestrian MONitoring

${ }^{2}$ Central European Commission
} 
em tempo real. Os principais pontos de estudo e pesquisa neste trabalho foram: projeto de uma interface homem-computador adequada, dispositivos de sensoriamento baseados, ou não, em vídeo e conectados em rede, e a escolha de uma rede de comunicações de baixo custo para o sistema. As câmeras de vídeo foram posicionadas em alturas que variavam de 3 a 6 metros, o que minimizou problemas de oclusão. O algoritmo para o processamento da seqüência de imagens é dividido em três etapas: geração de frames de referência, agrupamento/identificação e rastreamento/contagem. Uma vez que agrupamentos foram identificados e isolados, características geométricas foram extraídas com o propósito de rastrear e discriminar um pedestre de um agrupamento de pedestres. Esse sistema não pode executar contagem simultaneamente nas direções verticais e horizontais, limitando sua aplicação a lugares como corredores ou entradas onde fluxo de pessoas é unidirecional. Além disso, sua metodologia emprega subtração de fundo, que é fortemente dependente de variações de iluminação, e também das semelhanças de cores e padrões das roupas das pessoas e do fundo. Os resultados apresentados indicaram um grau de acerto de $85 \%$ na contagem das pessoas que transitavam na estação de trem St. Lazare na cidade de Paris, França.

Em Zhang e Sexton (1997) é sugerido o uso de um filtro específico, denominado de $\mathrm{MDF}^{3}$, para localizar a cabeça das pessoas na imagem, com fundos não constantes, como por exemplo na saída de uma escada rolante. O sistema tem um bom rendimento quando há um contraste bom entre a cabeça do pedestre e sua roupa. Seu desempenho fica prejudicado quando as pessoas não apresentam um formato da cabeça arredondado ou com dimensão fora da especificada no trabalho, devido à suas constituições físicas, ou por estarem usando um chapéu, ou apresentarem penteados incomuns. O sistema utiliza apenas uma câmera de vídeo, posicionada perpendicularmente ao plano de fundo.

Em Rossi e Bozzoli (1994) é apresentado um trabalho sobre a localização e contagem de pessoas que se movem, por exemplo, por uma saída de um recinto. O campo de visão da câmera de vídeo foi dividido em três áreas: uma área de alerta, uma área de tracking e uma área de contagem. Na primeira área foram determinados os objetos em movimento, através das diferenças de intensidade de brilho entre frames sucessivos e da análise de histogramas. A análise dos histogramas é feita apenas na área de alerta e, determina em cada coluna o número de pontos que se moveram. Os picos dos histogramas podem corresponder a objetos que se movem, enquanto os vales representam regiões onde não há movimentos. Na área de tracking, diferentes modelos foram gerados para cada pessoa e foi usado um método de correlação para identificar os modelos. Na área contagem, foram agrupados os

\footnotetext{
${ }^{3}$ Model-specific Directional Filter
} 
diferentes modelos de uma pessoa baseados em um procedimento hierárquico que usa um algoritmo aglomerativo. Sempre que um agrupamento de modelos pertencentes a uma pessoa cruza a linha de contagem, o total da contagem é incrementado de uma unidade e os modelos são descartados. O sistema foi experimentado em um ambiente externo de uma estação ferroviária, sob as seguintes restrições: câmera de vídeo colocada perpendicularmente ao plano do chão e objetos movendo-se apenas em duas direções; obtendo, aproximadamente, $90 \%$ de acertos.

Em Yasutomi et al. (1996) o andar de um pedestre é considerado um movimento periódico e difere de qualquer outro objeto que se move na cena. Assim, os pedestres são encontrados na cena procurando-se esta periodicidade. Para isto é estimada a freqüência-temporal e o período-espacial dos objetos que se movem na cena. Esse método é independente da intensidade, ou do contraste absolutos, dos objetos: a roupa, o estilo do cabelo, a forma do corpo, a iluminação e a distância da câmera de vídeo não afetam a confiabilidade da detecção. O algoritmo apresentado pode ser utilizado em tempo real. Apesar dessas vantagens, esse sistema apenas identifica pedestres na cena e os distinguem de outros objetos que se movem, mas não conta ou tampouco estima a direção dos pedestres.

Em Schofield et al. (1997) é apresentado um sistema para a contagem de pessoas paradas à espera de serviço de elevador, instalado em vários andares de um prédio, para melhor desempenho desse serviço. O sistema baseia-se no trabalho apresentado em Schofield et al. (1996) para fazer a distinção entre o fundo estático e os objetos a serem contados, o que minimiza problemas apresentados pelas variações dos níveis de iluminação, bem como do próprio fundo. Por utilizar redes neurais, o sistema pode ser treinado para mudanças do fundo e da iluminação, podendo assim ser usado em diferentes locais sem colocar restrições ao tipo de fundo da região inspecionada. O método tem três fases distintas: o pré-processamento da imagem, a identificação do fundo e a procura do objeto. O processo de treinamento se mostrou rápido e pode ser feito on-line. Imagens de baixa resolução foram usadas e o tempo de processamento de cada uma delas variou entre $0,2 \mathrm{~s}$ a $0,3 \mathrm{~s}$. Testes foram feitos com o números de pessoas na cena variando de 0 a 7 , não apresentando erros para cenas com número de pessoas entre 0 e 4 . O sistema foi concebido para ser implementado em um hardware dedicado.

Em Nesi et al. (1998) encontra-se um dos trabalhos mais relevantes nesta área, o desenvolvimento do RETIMAC ${ }^{4}$, o qual constitui a parte mais importante de um sistema dedicado, baseado em visão para contagem de pedestres. O sistema completo consiste de um subsistema de aquisição de imagens, o chip RETIMAC, capaz de estimar o campo do fluxo óptico em tempo-real, um banco de memórias e um

\footnotetext{
${ }^{4}$ Real-Time Motion Analysis
} 
microprocessador de 8 bits para supervisão do chip RETIMAC e para comunicação com os outros subsistemas via um canal serial. O RETIMAC foi projetado inicialmente para contar pessoas entrando e saindo em um dado local. Esse chip estima o movimento de objetos móveis presentes na cena pela análise espaço-temporal de uma seqüência de imagens.

Em Terada et al. (1999) é apresentado um método automático para contagem de pessoas que passam por uma porta. Esse método baseia-se em visão estéreo. Para a obtenção de imagens estéreo das pessoas que passam pela porta, foram colocadas duas câmeras de vídeo, do tipo CCD, perpendicularmente ao chão. Depois de obtida a sequiência de imagens foi estimada a altura dos pedestres. Em uma próxima etapa, através de uma análise espaço-temporal, foi estimada a direção do pedestre usando um processo de template maching. O sistema apresentou um acerto na contagem de pedestres de $97,7 \%$ para um fluxo baixo de pedestres. O processamento de imagem estéreo requer um alto custo computacional.

Um sistema para contagem de pedestres que circulam por corredores em ambientes fechados, e que utiliza múltiplas câmeras de vídeo, é descrito em Kettnaker e Zabih (1999). As câmeras de vídeo são distribuídas por esses corredores, de tal forma que seus campos de visão não se sobreponham. Um dos problemas enfrentados na utilização de várias câmeras de vídeo é que cada pedestre não pode ser contado baseado apenas nas imagens geradas por uma câmera de vídeo, pois assim se corre o risco de contar a mesma pessoa duas ou mais vezes. A contagem do fluxo de pedestres dever ser feitas através da análise conjunta das imagens de todas as câmeras de vídeo, o que gera um grande custo computacional. A abordagem está baseada na subtração do fundo da imagem. Os objetos que se movem na cena são detectados e segmentados aplicando-se uma variação do algoritmo proposto em Boykov et al. (1998). A informação da cor das roupas usadas pelos pedestres que circulam nos corredores é utilizada para determinar quando uma mesma pessoa saiu do campo de visão de uma câmera de vídeo e entrou no de uma outra, evitando assim que a mesma seja contada duas vezes. A estimação do sentido do pedestre é obtida através da seqüência de câmeras de vídeo que capturam as imagens de um pedestre. O sistema é altamente dependente dos níveis de iluminação.

Em Beymer (2000) é apresentada uma abordagem baseada em visão estéreo para contar pessoas. Duas câmeras de vídeo foram montadas no teto, perto de uma porta, apontando diretamente para o chão. O uso da visão estéreo permite determinar o volume dos objetos, ou de parte deles, presentes em uma cena. $\mathrm{O}$ sistema proposto procura, dentro da região monitorada, volumes que correspondam à cabeça e torso de uma pessoa adultas. Uma vez detectado esses volumes, os mesmos são seguidos através da região de interesse. Essas pessoas são detectadas 
e rastreadas na projeção ortográfica usando um modelo de filtro de Gauss e de Kalman. O sistema apresentou um erro médio de 1,4\% na contagem dos pedestres. A utilização de algum tipo de chapéu, de mochilas, ou de qualquer outro acessório que possa afetar o volume da cabeça ou do torso das pessoas, afeta sua correta detecção. Mais uma vez deve-se ressaltar o alto custo computacional necessário no processamento de imagens estéreo.

Em Masoud e Papanikolopoulos (2001) é apresentado um sistema em temporeal para o rastreamento e a contagem de pedestres em seqüências de imagens em níveis de cinza, de cenas capturadas por uma única câmera de vídeo fixa. O objetivo desse trabalho foi integrar esse sistema com uma aplicação de controle de pedestres em cruzamentos em áreas urbanas. O autor dividiu o sistema em três níveis: imagens, blobs e pedestres. No primeiro nível é obtida a diferença entre frames através da subtração de fundo e thresholding. As diferenças das imagens geradas no primeiro nível gera os blobs, sendo entes associados a objetos que se movem na cena. Estes blobs são as entradas para o terceiro nível, pedestres, e a saída, as coordenadas espaço-temporal dos pedestres presentes na cena. Os resultados experimentais, baseados em cenas em ambientes fechados e de cenas ao ar livre, demonstraram a robustez do sistema sob muitas situações difíceis, como oclusões parciais ou totais de pedestres. Esse sistema não tem como objetivo estimar a direção dos pedestres e também assume que todos os objetos na cena são pedestres, o que significa que outros objetos, como bicicletas, podem também ser reconhecidos como pedestres. O sistema foi testado em várias seqüências de imagens, apresentando erro médio de $5 \%$.

Em Kim et al. (2002) é descrito um sistema para a contagem de pessoas que passam por uma porta de segurança dentro de um edifício, similar ao desenvolvido em Terada et al. (1999). O sistema além de contar, estima a direção dos pedestres. É composto por uma única câmera de vídeo colocada perpendicularmente ao chão, de forma a minimizar o problema de oclusão. A imagem capturada pela câmera de vídeo é processada e o número dos pedestres é determinado. Esse processamento é dividido em três etapas. A primeira etapa consiste em determinar se algum objeto em movimento apareceu na cena. A segunda, consiste em seguir esse objeto até que uma linha de contagem seja alcançada. Se o objeto chegar até a linha de contagem, então na terceira fase será determinar se esse objeto corresponde a um pedestre, ou não, e assim proceder sua contagem. A detecção de um objeto na cena é obtida através da subtração do fundo e de um thresholding. Para minimizar o problema da variação da iluminação, que afeta sistemas baseados em estimação do fundo, são realizadas, em paralelo, duas subtrações: a da imagem no instante de tempo $t$ e da imagem do fundo; e das imagens nos instantes de tempo $t-1$ e $t$. Quando não 
há objeto movendo-se na cena a imagem do fundo é atualizada. Esse método de estimação do fundo apresentou uma boa robustez com relação a variações lentas de iluminação, mas não pode lidar com mudanças bruscas. O sistema utiliza 10 frames por segundo e obteve um acerto de $96 \%$.

Em Pádua (2002) é descrita uma metodologia para contagem de pedestres em ambientes não restritos e abertos, utilizando uma única câmera de vídeo para a captura das seqüência de imagens e a digitalização dessas imagens, com profundidade de 8 bits, foi realizada por uma frame-grabber conectada ao barramento padrão PCI de um PC. O fluxo óptico é utilizado na detecção dos pedestres presentes na cena. Para diferenciar pedestres de outros objetos que podem estar em movimento na cena, foram feitas análises espaço-temporais do campo do fluxo óptico. O sistema é também capaz de estimar a direção dos pedestres e, para isto, a cena foi dividida em duas sub-áreas. Com o objetivo de diminuir o custo computacional, a freqüência da captura dos frames foi definida em função da velocidade média de pedestres, bem como da largura das sub-regiões. O sistema apresentou um acerto médio de $84 \%$. Esse sistema estima apenas o fluxo unidirecional de pedestres, o que o torna pouco eficiente para aplicações em ambientes urbanos ou espaços não restritos, onde o fluxo de pedestres é multidirecional. Por utilizar uma frame-grabber Matrox, modelo Meteor II, o custo do sistema fica comprometido, já que essas placas são de alto custo.

\subsection{Considerações finais}

Sistemas para contagem automática de pedestres podem encontrar aplicações em diversas situações: no controle do fluxo de pedestres em entradas de edifícios e estabelecimentos comerciais, na contagem de usuários de ônibus, na estimação do tráfego de pedestres em espaços urbanos, etc.

A revisão bibliográfica sobre esses sistemas apresentada neste capítulo, evidenciou que esses sistemas são dedicados, ou seja, que cada aplicação exige um método específico, função principal do espaço a ser monitorado.

Sistemas baseados em sensores não são adequados para estimar o fluxo de pedestres quando utilizados em espaços abertos e não restritos, pois necessitam de uma infra-estrutura, porém, bons resultados foram obtidos com esses sistemas para ambientes restritos, como em Hashimoto et al. (2000).

Sistemas baseados em visão aparecem como uma boa alternativa para ambientes abertos, porém, poucos foram os autores que se dedicaram a desenvolver sistemas baseados em câmeras de vídeo para a estimação do fluxo de pedestres 
para esses espaços, exceção feita aos trabalhos apresentados em Sexton et al. (1995)

e Pádua (2002), que no entanto, trataram apenas do fluxo unidirecional. 


\section{Capítulo 3}

\section{Fundamentos teóricos de sistemas para contagem de pedestres}

\subsection{Considerações iniciais}

Neste capítulo são apresentados os principais conceitos relacionados com a estimação do movimento em seqüências de imagens digitais e as características humanas que foram utilizadas no algoritmo implementado.

\subsection{Estimação de movimento em seqüências de imagens digitais}

A percepção visual de movimento é uma função essencial do sistema visual humano, sendo importante na estimação do movimento relativo entre objetos, na estimação do movimento próprio, nos processos de orientação e na discriminação entre objetos espacialmente separados (Núñez, 1996).

Câmeras de vídeo podem capturar movimentos de objetos em um campo visual, ou melhor, em uma cena, e podem reproduzir, embora, de forma não tão perfeita, essas funções do sistema visual humano.

Movimento em uma seqüência de imagens obtidas por uma câmera de vídeo é induzido por movimentos de objetos em uma cena $3 \mathrm{D}^{1}$ e/ou através do movimento da câmera. Portanto, parâmetros da câmera de vídeo, como, comprimento focal e seu movimento de rotação e/ou translação, têm importância na modelagem do movimento do objeto na imagem. Uma vez que esses parâmetros são conhecidos,

\footnotetext{
${ }^{1}$ Tridimensional
} 
somente o movimento do objeto precisa ser recuperado (Pádua, 2002).

Através da recuperação desse movimento, perguntas, como: quantos objetos em movimento existem na cena, em que direção estão se movendo e em qual velocidade, podem ser respondidas (Rittner, 2004).

As imagens capturadas pela câmera, em geral, constituem um sinal contínuo que precisa ser discretizado para poder ser processado por um computador. Esse sinal discretizado é denominado sinal de vídeo digital.

Em termos gerais, define-se um sinal de vídeo digital como uma seqüência de imagens digitais bidimensionais ordenadas no tempo. Cada uma dessas imagens resulta da discretização na amplitude, no espaço e no tempo da informação visual. Cada imagem amostrada é constituída por um conjunto de pontos com níveis discretos de intensidade, designados correntemente por pixel ${ }^{2}$. Esses pontos são, então, distribuídos segundo matrizes bidimensionais retangulares, eqüidistantes no espaço e ordenados no tempo, como mostra a Figura 3.1 (Roma, 2001). Numa seqüência em escala de cinza, cada um dos pixels representa o nível de intensidade luminosa num dado ponto da imagem, proporcional ao brilho, ou níveis de cinza, da imagem naquele ponto (Gonzales e Woods, 1992). Na maioria dos sistemas, essa intensidade é representada utilizando uma resolução de 8 bits, onde cada pixel pode, assim, assumir um dos 256 níveis de cinza distintos (Galo et al., 1999).

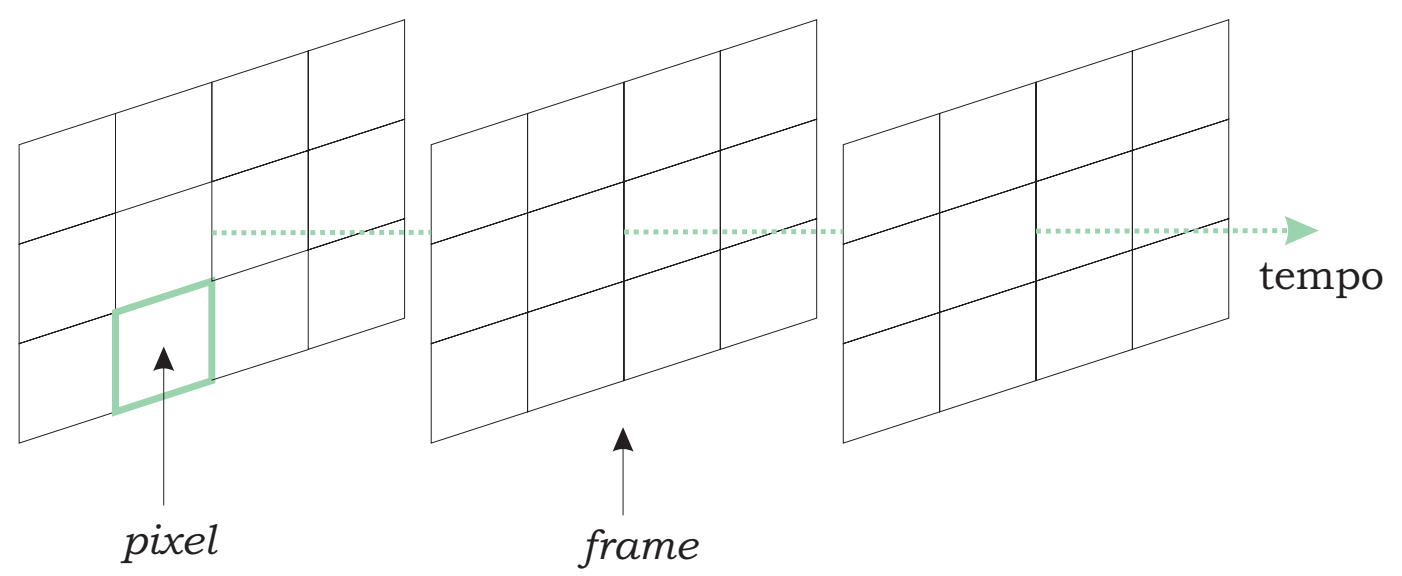

Figura 3.1: Definição do conceito de sinal de vídeo digital (Roma, 2001).

A estimação de movimento de objetos em seqüências de imagens digitais tornou-se um dos principais problemas em processamento digital de imagens, e tem sido objeto de contínuas pesquisas (Oliveira, 2003) sendo de grande relevância em muitos problemas como reconstrução 3D, rastreamento de objetos e navegação de robôs, e sendo também, a base desse trabalho.

\footnotetext{
${ }^{2}$ Picture Element.
} 
Basicamente são três as etapas de estimação do movimento em uma cena (Oliveira e Roda, 2001):

- a detecção da existência de movimento;

- sua localização;

- sua quantificação.

Para que um algoritmo de estimação de movimento de objetos em um cena tenha êxito e seja prático do ponto de vista do ambiente do mundo real, é necessário que o mesmo seja robusto a ruído, preciso e rápido, principalmente para sistemas que trabalham em tempo real (Camus, 1994).

A precisão está relacionada com o mínimo erro, ou o acerto aceitável da estimação. Obviamente que um algoritmo de visão deve retornar medidas tão corretas quanto sejam apropriadas a uma tarefa, ou seja, seu resultado deve combinar os requisitos de robustez, velocidade e precisão dependendo muito da aplicação desejada (Oliveira e Roda, 2001; Oliveira, 2003).

Em Tekalp (1995) são citadas as três principais dificuldades que afetam o problema de estimação de movimento, sendo elas:

- a descontinuidade no campo de movimento, que é originada pela presença de ruído na intensidade da imagem; Costa (1998) define campo de movimento, como sendo a projeção no plano de imagem do movimento de um ponto no espaço tridimensional;

- a presença de oclusões entre diferentes objetos em movimento, que podem ter diferentes velocidades, e entre objetos em movimento e o fundo estático. Esse problema está ilustrado na Figura 3.2;

- o chamado problema de abertura, que está relacionado com a impossibilidade de recuperar a direção do movimento se o objeto é observado através de uma abertura menor que o tamanho do objeto; e as referências ao objeto sob observação, como textura, não são suficientes para perceber a componente transversal do movimento do objeto. Esse problema está ilustrado na Figura 3.3.

Os algoritmos para estimação do movimento em seqüências de imagens digitais geram o chamado fluxo óptico, definido em Costa (1998), como sendo o movimento dos padrões da intensidade, no plano de imagem, ao longo do tempo, sendo equiparado ao campo de movimento. 

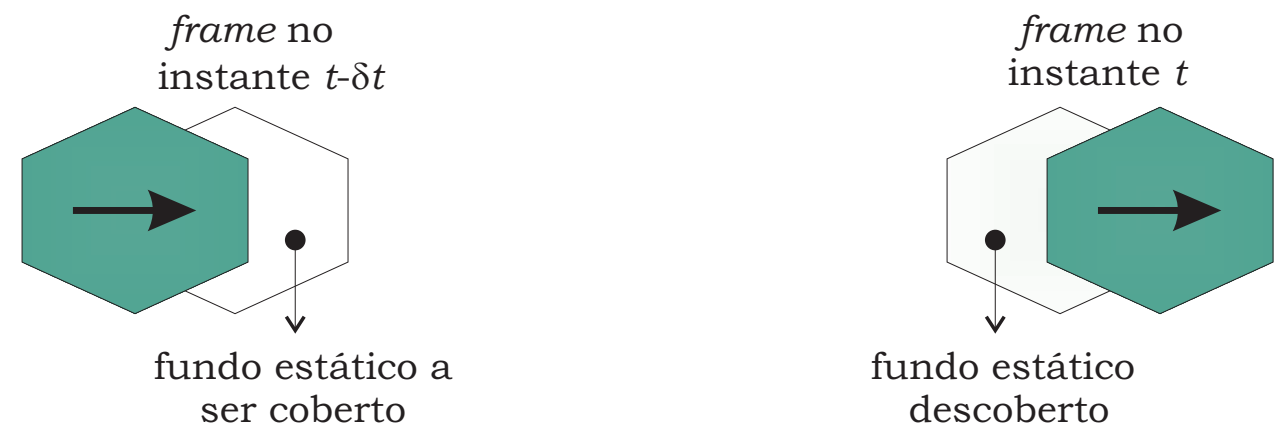

Figura 3.2: Problema de oclusão (Tekalp, 1995).

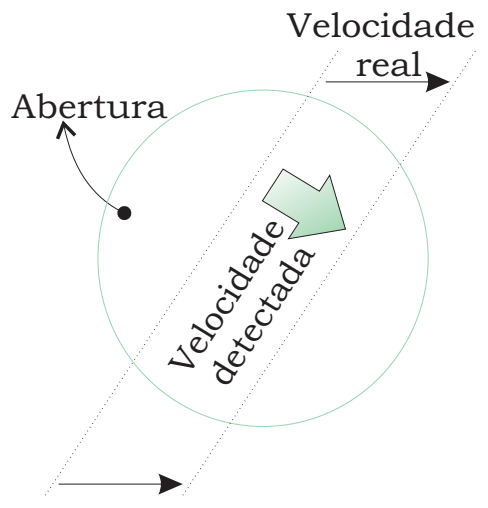

Figura 3.3: Problema de abertura (Nesi, 1994).

Em termos matemáticos, o fluxo óptico consiste em um conjunto de vetores calculados a partir de uma distribuição espaço-temporal em uma seqüência de imagens digitais e pode ser utilizado para estudar o movimento de um objeto no espaço 3D (Jonson, 2001).

Para cada pixel em uma imagem pode-se, teoricamente, calcular o correspondente vetor velocidade. Na prática, existem alguns métodos de estimativa de fluxo óptico que são capazes de obter vetores para todos os pixels. A maioria dos métodos gera um vetor para um conjunto de pixels. O conjunto de todos os vetores velocidade gera um mapa de fluxo, que se torna tanto mais denso, quanto mais vetores velocidade contiver (Rittner, 2004).

O fluxo óptico tem sido utilizado em múltiplas aplicações, tais como (Garcés, 1999): estimação de propriedades de cenas 3D; na segmentação do movimento; cálculo do foco de expansão e do tempo de colisão para robôs móveis; compensação de movimento em imagens codificadas; cálculo de disparidade em imagens estéreo. 


\subsection{Métodos para a estimação do fluxo óptico}

$\mathrm{Na}$ literatura pesquisada foram identificados três métodos principais para estimação do fluxo óptico (Barron et al., 1994; Nesi, 1994; Bab-Hadiashar e Suter, 1996; Eikvil e Thune, 1998; Trucco e Verri, 1998; Nitsuwat, 1998; Marcel, 2001):

- métodos baseados em gradiente - os métodos baseados em gradiente calculam a velocidade da imagem através das derivadas espaço-temporais de sua intensidade. O domínio da imagem é considerado contínuo, portanto, diferenciável, no espaço e no tempo. Nesse trabalho serão apresentados, na Seção 3.3.1, dois métodos: o de Lucas e Kanade (Lucas e Kanade, 1981) e o de Horn e Schunck (Horn e Schunck, 1981);

- métodos baseados em correspondência - métodos baseados em correspondência procuram características facilmente identificáveis em imagens 2D e segue essas características à medida que elas se movem frame a frame. O método baseado em correspondência proposto em Anandan (1989) será descrito na Seção 3.3.2;

- métodos baseados em filtros - a estimação do fluxo óptico está baseada no uso de filtros sintonizados em velocidade ${ }^{3}$. Serão apresentados, na Seção 3.3.3, dois métodos: o de Heeger (1988) e o de Fleet e Jepson (1990).

Com relação aos métodos baseados em gradiente, são identificadas duas variações (Beauchemin e Barron, 1995; Corbett, 2000; Wegger, 2000; Brox, 2002):

- os baseados em regularização;

- os baseados em multi-restrição.

Para os métodos baseados em filtros, também foram identificadas duas variações:

- baseados em energia;

- baseados em fase.

Na Figura 3.4 os diferentes métodos, para estimação do fluxo óptico em seqüências de imagens digitais e suas variações, estão representados de forma gráfica.

\footnotetext{
${ }^{3}$ velocity-tuned filters
} 


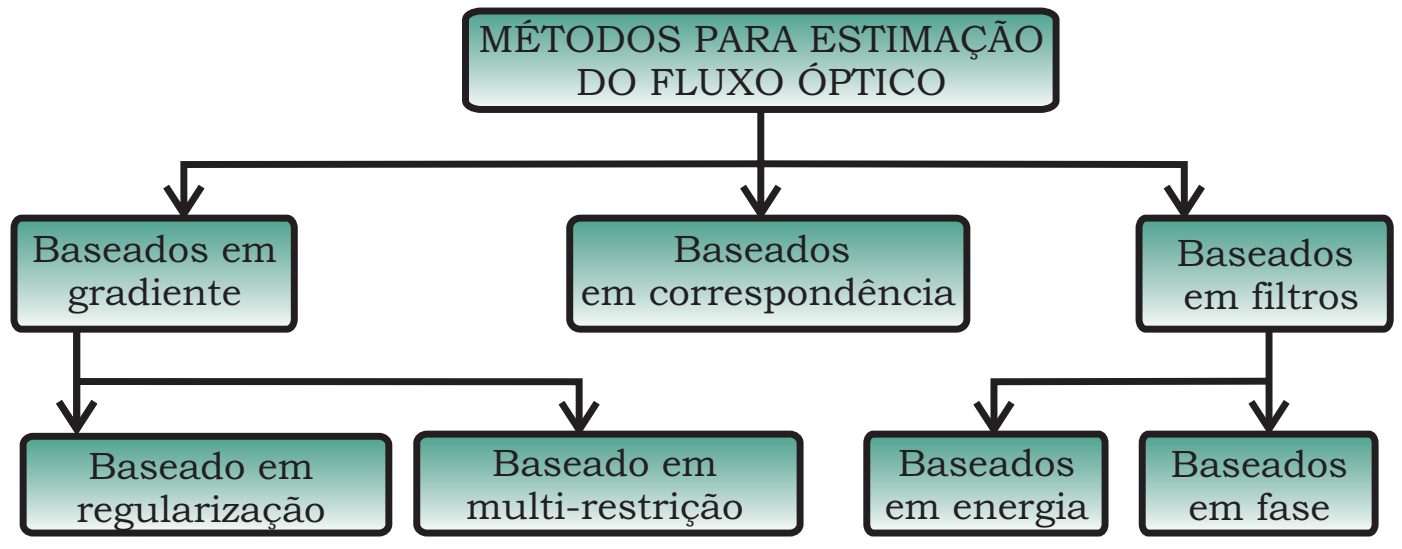

Figura 3.4: Métodos para estimação do fluxo óptico encontradas na literatura pesquisada.

\subsubsection{Métodos baseados em gradiente}

Os métodos baseados em gradiente estão relacionados à observação da mudança dos valores de intensidade da imagem $E(x, y, t)$, onde $E(x, y, t)$ é a função intensidade nas coordenadas $(x, y)$ no instante de tempo $t$. A solução para as equações resultantes, fornecem a estimação para o campo de velocidades do plano de imagem, que é também chamado de fluxo óptico do campo de velocidade da imagem.

Supondo que $(x, y)$ seja a posição de um ponto na imagem no instante $t$, e que $\mathbf{v}$ seja a velocidade desse ponto projetada no plano de imagem. O mesmo ponto $(x, y)$ após um tempo $\delta t$ move-se para uma nova posição $\left(x+\frac{d x}{d t} \delta t, y+\frac{d y}{d t} \delta t\right)$. Assumindo a conservação da intensidade da imagem nesse ponto (Horn e Schunck, 1981) como restrição, ou seja, que $\frac{d E}{d t}=0$, temos que

$$
E(x, y, t)=E\left(x+\frac{d x}{d t} \delta t, y+\frac{d y}{d t} \delta t, t+\delta t\right)
$$

Expandindo a Equação 3.1 através da série de Taylor e representando $E_{x}=\frac{\partial E}{\partial x}$, $E_{y}=\frac{\partial E}{\partial y}$ e $E_{t}=\frac{\partial E}{\partial t}$, pode-se reescreve-la na forma da Equação 3.2.

$$
\frac{d E}{d t}=\frac{\partial E}{\partial x} \frac{d x}{d t}+\frac{\partial E}{\partial y} \frac{d y}{d t}+\frac{\partial E}{\partial t}+\operatorname{Err}\left(\delta t^{2}\right)=0
$$

Na Equação 3.2, o termo $\operatorname{Err}\left(\delta t^{2}\right)$ representa o erro existente neste cálculo, pois apenas os termos até a primeira derivada, são utilizados na expansão da série de Taylor. Assumindo que esse erro pode ser desprezado e fazendo $u=\frac{d x}{d t}, r=\frac{d y}{d t}$, pode-se escrever a Equação 3.3.

$$
E_{x} u+E_{y} r+E_{t}=0
$$


A Equação 3.3 recebe, na literatura de fluxo óptico, o nome de Optical Flow Constraint (OFC).

A Equação 3.2 pode também ser representada por:

$$
\nabla E \cdot v+\frac{\partial E}{\partial t}=0
$$

Na Equação 3.4, o vetor v, com componentes ortogonais $u$ e $r$, é o fluxo óptico no instante de tempo $t$ no ponto $p$ com coordenadas $(x, y)$ no plano de imagem $\mathrm{e}$ $\nabla E=\left[\begin{array}{ll}\frac{\partial E}{\partial x} & \frac{\partial E}{\partial y}\end{array}\right]^{T}$ é o gradiente no mesmo ponto. O ponto $p$ é a imagem de um ponto $P$ movendo-se em uma cena $3 \mathrm{D}$ com uma velocidade $V$.

A Equação 3.4 representa também a restrição da intensidade e no caso de apenas se utilizar essa restrição para a estimação do fluxo óptico, apenas a projeção do fluxo óptico na direção do gradiente poderá ser calculada (Camus e Bülthoff, 1995). Esse fato está relacionado com o chamado problema de abertura, que está ilustrado na Figura 3.3. Nessa figura, pode-se observar que apenas a componente da velocidade, que é normal às arestas dos objetos, poderá ser detectada. Essa componente é chamada de fluxo óptico normal e é dada pela Equação 3.5, que é obtida através da Equação 3.4. Essa componente é ilustrada pela Figura 3.5.

$$
v_{\perp}=-\frac{E_{t}}{\|\nabla E\|} \frac{\nabla E}{\|\nabla E\|}
$$

Na Equação 3.5, $\frac{\nabla E}{\|\nabla E\|}$ identifica a direção do gradiente $\nabla E$ se $\nabla E \neq 0$ (del Bimbo et al., 1995).

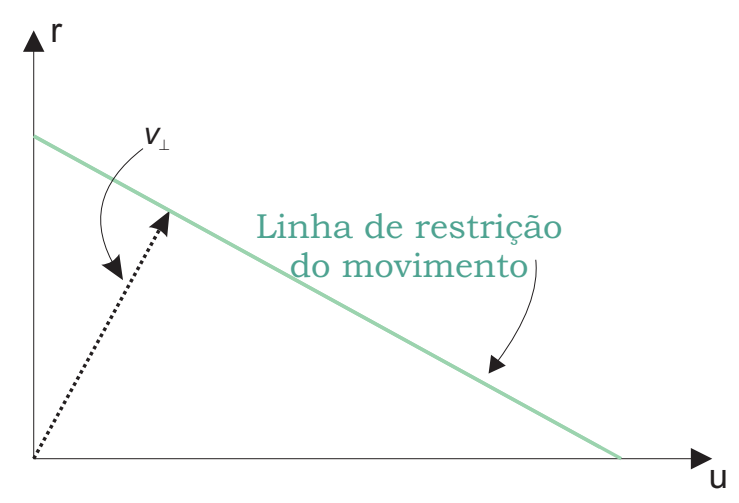

Figura 3.5: Linha da restrição e componente normal do fluxo óptico.

Na literatura, partindo do OFC, muitas outras restrições foram propostas a fim de melhorar a estimativa do campo do fluxo óptico, cada uma com suas próprias propriedades e comportamentos (del Bimbo e Santini, 1994).

Dois métodos que impõem novas restrições à OFC são os baseados em re- 
gularização e os baseados em multi-restrição, que serão descritos na Seções 3.3.1.1 e 3.3.1.2.

\subsubsection{Métodos baseados em regularização}

Métodos baseados em regularização consideram que a estimação do fluxo óptico é um problema de mal-condicionado (del Bimbo e Santini, 1994; Nesi, 1994), que se deve ao fato de que dados disponíveis não são suficientes para obter uma solução (Wegger, 2000). Nestes métodos é definida um funcional em que uma restrição de suavização é utilizada para regularizar a solução da equação diferencial parcial e a influência da restrição de suavização é ponderada com uma constante positiva (Laplante e Stoyenko, 1996; Nesi, 1994). Nesses métodos, as soluções são obtidas iterativamente (del Bimbo e Santini, 1994; Nesi, 1994).

Dentre as várias soluções baseadas em regularização propostas na literatura, para a solução da estimação do fluxo óptico, a mais conhecida foi proposta por Horn e Schunck em Horn e Schunck (1981) (Laplante e Stoyenko, 1996; Nesi, 1994; Galvin et al., 1998) e está fundamentada na incorporação de uma restrição de suavização à OFC, como mostrado pela Equação 3.6.

$$
\iint\left[\left(E_{x} u+E_{y} r+E_{t}\right)^{2}+\alpha^{2}\left(u_{x}^{2}+u_{y}^{2}+r_{x}^{2}+r_{y}^{2}\right)\right] d_{x} d_{y}
$$

Na Equação 3.6 o primeiro termo é a equação do fluxo óptico, o segundo termo é a restrição de suavização e $\alpha$ a constante que controla o peso da restrição de suavização.

A Equação 3.6 pode ser minimizada pelo cálculo de variações, o que conduz a um sistema de duas equações diferenciais 3.7 (Nesi, 1994).

$$
\begin{aligned}
& \nabla^{2} u=\frac{E_{x}}{\alpha^{2}}\left(E_{x} u+E_{y} r+E_{t}\right) \\
& \nabla^{2} r=\frac{E_{y}}{\alpha^{2}}\left(E_{x} u+E_{y} r+E_{t}\right)
\end{aligned}
$$

Segundo Nesi (1994), o par de Equações 3.7 pode ser decomposto e uma solução iterativa pode ser encontrada usando uma aproximação discreta do operador laplaciano pelo método de diferenças finitas. Desse modo, o par de Equações 3.8 pode ser utilizado para estimar as componentes ortogonais do vetor $v$ em cada instante de tempo $t$. 


$$
\begin{aligned}
& u_{(i, j, t)}^{n+1}=u_{(i, j, t)}^{-n}-\frac{E_{x(i, j, t)}\left(E_{x(i, j, t)} u_{x(i, j, t)}^{-n}+E_{y(i, j, t)} r_{x(i, j, t)}^{-n}+E_{t(i, j, t)}\right)}{\beta} \\
& r_{(i, j, t)}^{n+1}=r_{(i, j, t)}^{-n}-\frac{E_{x(i, j, t)}\left(E_{x(i, j, t)} u_{x(i, j, t)}^{-n}+E_{y(i, j, t)} r_{x(i, j, t)}^{-n}+E_{t(i, j, t)}\right)}{\beta}
\end{aligned}
$$

No par de Equações $3.8, \beta=\alpha^{2}+E_{x(i, j, t)}^{2}+E_{y(i, j, t)}^{2}, n$ é número de iterações e $u_{(i, j, t)}^{-n}$ e $r_{(i, j, t)}^{-n}$ são dados por:

$$
\begin{aligned}
u_{(i, j, t)}^{-n}= & \frac{u_{(i-1, j-1, t)}+u_{(i-1, j+1, t)}+u_{(i+1, j-1, t)}+u_{(i+1, j+1, t)}}{12}+ \\
& +\frac{u_{(i-1, j, t)}+u_{(i-1, j, t)}+u_{(i, y-1, t)}+u_{(i, y+1, t)}}{6} \\
r_{(i, j, t)}^{-n}= & \frac{r_{(i-1, j-1, t)}+r_{(i-1, j+1, t)}+r_{(i+1, j-1, t)}+r_{(i+1, j+1, t)}}{12}+ \\
& \frac{r_{(i-1, j, t)}+r_{(i-1, j, t)}+r_{(i, y-1, t)}+r_{(i, y+1, t)}}{6}
\end{aligned}
$$

\subsubsection{Métodos baseados em multi-restrição}

Os métodos baseados em multi-restrição (multiconstraint based), propõem a definição de uma equação de restrição para a equação da OFC, de tal forma a tornála uma equação bem-condicionada (Nesi, 1994). Os métodos baseados em multirestrição, podem ser classificados de acordo com o método escolhido para definir o sistema de equações e as técnicas matemáticas usadas para sua solução (Nesi, 1994; Kuzina, 2000):

método A: supõe que o contraste, a média dos valores da intensidade da imagem, a variância do brilho, etc., não variam no tempo, como foi suposto para o brilho da imagem, $\frac{d E}{d t}=0$, na OFC. Isto permite que várias equações diferenciais parciais estruturalmente iguais à $\mathrm{OFC}$ possam ser definidas para uma mesmo ponto da imagem; assim um conjunto de equações sobredeterminado é obtido, com $u$ e $r$ como incógnitas;

método B: são obtidas novas restrições, em forma de equações, a partir das derivadas da OFC, com respeito aos eixos $x, y$ e $t$, ou, avaliando em série de Taylor as derivadas da restrição e assumindo que essas derivadas são iguais a zero;

método C: assume-se que a mudança do fluxo óptico é aproximadamente linear, assim uma solução de suavização para a estimação do fluxo óptico pode ser 
obtida a partir de uma aproximação linear da restrição usada na vizinhança $N \times N$ do ponto sob observação (veja a Figura 3.6). Essa suposição é válida apenas se o campo de fluxo óptico é suave.

A qualidade de estimação de fluxo óptico depende das equações escolhidas. Já o desempenho desses algoritmos é função do número de equações e da técnica adotada para resolver o sistema. Nesi (1994) divide essas técnicas em duas classes :

classe A: soluções algébricas, em que o sistema de equações é resolvido com métodos numéricos para a pseudo-inversão da matriz de coeficientes;

classe B: soluções baseadas em agrupamento, em que cada solução possível é considerada como um ponto no domínio multidimensional. Esses pontos são agrupados em ordem para selecionar a solução mais provável.

Basicamente, as soluções algébricas são executadas em quatro etapas (del Bimbo e Nesi, 1993; Nesi, 1994; Laplante e Stoyenko, 1996):

etapa 1: a convolução das imagens com um filtro gaussiano;

etapa 2: a estimação das derivadas da intensidade da imagem;

etapa 3: a estimação do sistema de equações utilizando o método de pseudoinversão;

etapa 4: as estimação das componentes ortogonais do vetor velocidade.

O método proposto em Lucas e Kanade (1981) é uma das abordagens encontradas na literatura de fluxo óptico baseada em multi-restrição. Lucas e Kanade (1981) utiliza o método C para definir o sistemas de equações e a técnica da classe A para a sua solução, apresentados anteriormente. Então, as restrições avaliadas na vizinhança de um ponto representam a mesma velocidade. Essa suposição permite incluir uma vizinhança de $N \mathrm{x} N$ a um ponto, como mostrado na Figura 3.6, e assim obter um sistema sobre-determinado das $N^{2}$ equações de restrição, conforme mostrado na Equação 3.10:

$$
\left\{\begin{array}{c}
\frac{\partial E_{1(i, j, t)}}{\partial x} u+\frac{\partial E_{1(i, j, t)}}{\partial y} r+\frac{\partial E_{1(i, j, t)}}{\partial t}=0 \\
\vdots \\
\frac{\partial E_{N^{2}(i, j, t)}}{\partial x} u+\frac{\partial E_{N^{2}(i, j, t)}}{\partial y} r+\frac{\partial E_{N^{2}(i, j, t)}}{\partial t}=0
\end{array}\right.
$$

Um valor elevado para $N$ conduzirá a uma estimação do fluxo óptico mais suave, porém, com perda na definição da estimação dos vetores de velocidade. 


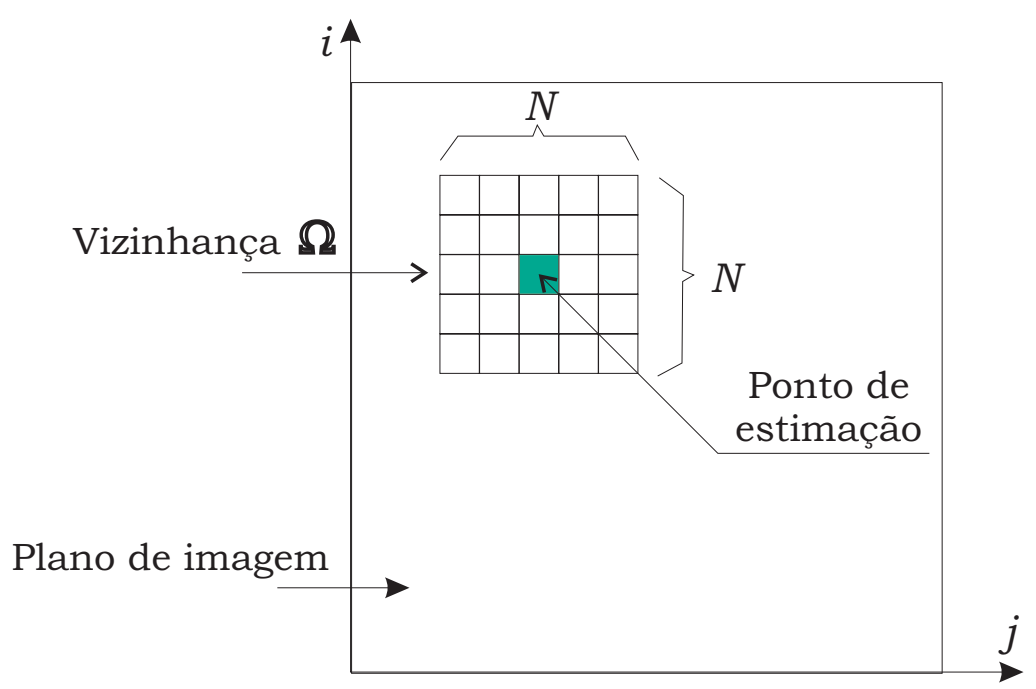

Figura 3.6: Vizinhança $\Omega$ de $N \mathrm{x} N$ pixels.

Representado-se de forma matricial o conjunto de Equações 3.10 e considerandose a utilização de uma máscara gaussiana $W$, como proposto por Lucas e Kanade, tem-se:

$$
W^{2} A v=W^{2} \boldsymbol{b}
$$

Na Equação 3.11:

$$
\left\{\begin{array}{c}
A=\left[\begin{array}{lll}
\frac{\partial E_{1}(i, j, t)}{\partial x} & \cdots & \frac{\partial E_{N^{2}}(i, j, t)}{\partial x} \\
\frac{\partial E_{1}(i, j, t)}{\partial y} & \cdots & \frac{\partial E_{N^{2}}(i, j, t)}{\partial y}
\end{array}\right]^{T} \\
W=\left[\begin{array}{ccc}
W_{1}(i, j) & 0 & 0 \\
0 & \ddots & 0 \\
0 & 0 & W_{N^{2}}(i, j)
\end{array}\right] \\
\boldsymbol{b}=-\left[\begin{array}{lll}
\frac{\partial E_{1}(i, j, t)}{\partial t} & \cdots & \frac{\partial E_{N^{2}}(i, j, t)}{\partial t}
\end{array}\right]^{T}
\end{array}\right.
$$

Em Lucas e Kanade (1981), é utilizada uma solução algébrica, em que o sistema de equações é resolvido com métodos numéricos para a pseudo-inversão da matriz de coeficientes. Tem-se, portanto, a partir da Equação 3.11:

$$
A^{T} W^{2} A v=A^{T} W^{2} \boldsymbol{b}
$$


Da Equação 3.13 pode-se escrever que:

$$
\boldsymbol{v}=\left(A^{T} W^{2} A\right)^{-1} A^{T} W^{2} \boldsymbol{b}
$$

Esse sistema de equações pode ser resolvido diretamente, já que apresenta duas equações com duas incógnitas.

\subsubsection{Método baseado em correspondência}

Esse método baseia-se em correspondência, utilizando-se da identificação de um conjunto de características esparsas e facilmente identificáveis dos objetos em movimento em uma cena. Pelo rastreamento dessas características é buscada uma correspondência entre os quadros para estimar o movimento das características no plano da imagem. Essas características podem ser linhas e formas ou padrões e curvaturas (Nesi, 1994).

A abordagem de maior destaque, adota como característica o padrão do brilho da imagem (Nesi, 1994). A descrição de sua implementação é apresentada em Anandan (1989) e recebe o nome de método de correspondência de blocos (block matching).

O método baseado em correspondência de blocos utiliza os segmentos da imagem como detalhes para buscar suas correspondências. Nesse caso, a estimação do campo de movimento consiste em encontrar as coordenadas $x^{\prime}, y^{\prime}$ do centro do segmento no tempo $t$ que minimizam a correspondência com o segmento no tempo $t-\delta t$ com coordenadas $x, y$ (Kuzina, 2000), como ilustrado na Figura 3.7. A Equação 3.15 é utilizada para obter a estimação.

$$
C\left(x, y, x^{\prime}, y^{\prime}\right)=\sum_{q=-\frac{Q}{2}}^{\frac{Q}{2}} \sum_{r=-\frac{R}{2}}^{\frac{R}{2}}\left(E(x+q, y+r, t-\delta t)-E\left(x^{\prime}+q, y^{\prime}+r, t\right)\right)
$$

Na Equação 3.15, $E(x, y, t)$ é o valor da intensidade da imagem no tempo t no ponto de coordenada $(x, y)$, Q e $\mathrm{R}$ são as dimensões do padrão de referência, conforme ilustrado pela Figura 3.7. O processo de minimização consiste em encontrar o valor mínimo da função $C\left(x, y, x^{\prime}, y^{\prime}\right)$ ao redor do ponto $(x, y)$ para $x^{\prime}=x-$ $\frac{F}{2}, \ldots, x+\frac{F}{2}$ e $y^{\prime}=y-\frac{F}{2}, \ldots, y+\frac{F}{2}$, onde $F$ é a dimensão do segmento da imagem para a qual se busca o valor mínimo. As coordenadas $\left(x^{\prime}, y^{\prime}\right)$ identificam a posição do segmento no tempo t. As diferenças $S_{x}=x^{\prime}-x$ e $S_{y}=y^{\prime}-y$ são os componentes de deslocamento do segmento, ou seja, sua velocidade. 


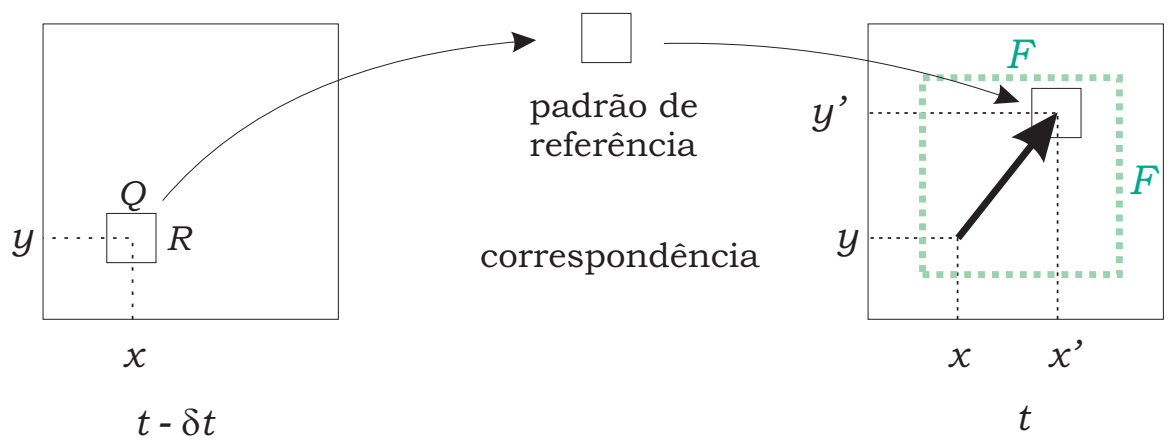

Figura 3.7: Correspondência entre blocos (Kuzina, 2000).

O método de correspondência de blocos é sensível a ruído, mas esse problema pode ser minimizado com o aumento do tamanho do padrão de referência. Mecanismos para melhorar a robustez desse método podem ser encontrados em Laplante e Stoyenko (1996).

\subsubsection{Métodos baseados em filtros}

Nesses métodos o cálculo do fluxo óptico é baseado na resposta de filtros sintonizados para determinadas velocidades, considerando-se assim que as freqüências espaço-temporais estão relacionadas com a velocidade dos pixels através da equação 3.16 (Fonseca, 1998; Rittner, 2004).

$$
\omega_{t}=\omega_{u} u+\omega_{r} r
$$

Na Equação 3.16 as variáveis $u$ e $r$ são as componentes ortogonais do vetor velocidade $v, \omega_{u}$ e $\omega_{r}$ são as componentes ortogonais da freqüência espacial e $\omega_{t}$ é a freqüência temporal correspondente.

A Equação 3.16 foi deduzida através da Transformada de Fourier, aplicada a dois frames consecutivos, considerando que existe conservação da intensidade dos pixels entre as imagens (Heeger, 1988).

Segundo a Equação 3.16, se o sinal for visto no espaço $\omega_{u}, \omega_{r}$ e $\omega_{t}$, tem-se a equação de um plano. O vetor velocidade $v$ pode ser determinado se o plano for determinado.

Em Heeger (1988) são utilizados doze filtros de Gabor sintonizados em freqüências centrais que estão contidas dentro de um cilindro no espaço $\omega_{u}, \omega_{r}$ e $\omega_{t}$, onde o eixo desse cilindro é o eixo $\omega_{t}$. Cada filtro está sintonizado para dar a sua resposta máxima para um determinado valor do fluxo óptico e, dessa forma, através do uso de diferentes filtros, podem-se obter respostas diferentes, que dependem da 
freqüência espaço temporal das imagens. O melhor dos doze filtros, dá origem ao resultado escolhido, definindo assim, os parâmetros do plano (Laplante e Stoyenko, 1996).

Os métodos baseados em fase são muito semelhantes ao método baseado em energia espaço-temporal (Laplante e Stoyenko, 1996). Essa semelhança se dá pelo fato de que os métodos baseados em fase utilizam também filtros sintonizáveis, nesse caso, passa-banda. No entanto, o vetor velocidade $v$ é definido em termos do valor da fase para a saída do filtro. Em Fleet e Jepson (1990, 1992) é descrita uma implementação que utiliza método baseado em fase.

\subsection{Estudos comparativos entre os métodos para estimação do fluxo óptico}

Dois diferentes ramos foram seguidos no desenvolvimento de algoritmos para a estimação do fluxo óptico em seqüências de imagens digitais, um enfatizando a exatidão e o outro a velocidade de execução (Liu et al., 1998).

Encontram-se na literatura estudos comparativos do desempenho dos diferentes algoritmos para estimação do fluxo óptico em seqüencias de imagens digitais, como os apresentados em Barron et al. (1994), Liu et al. (1998) e Galvin et al. (1998).

Em Barron et al. (1994) foram testados diferentes métodos para estimação de movimento, tanto em seqüências de imagens digitais sintéticas quanto reais, relatando diferentes medidas comparativas quanto à precisão e densidade das medidas dos vetores velocidade. Os métodos de estimação de movimento testados foram os baseados em: gradiente, correspondência e energia. Os métodos baseados em gradiente testados em Barron et al. (1994) foram: Horn e Schunck (1981) e Lucas e Kanade (1981). Já o método baseado em correspondência testado foi o de Anandan (1989) e os baseados em energia foram Heeger (1988) e Fleet e Jepson (1990).

Outros métodos para estimação do fluxo óptico foram testados em Barron et al. (1994), mas não foram descritos nesse trabalho. São eles os métodos propostos em Singh (1990), Nagel (1983), Uras et al. (1989) e Waxman et al. (1988).

Segundo Barron et al., dos métodos testados, o mais confiáveis são: o baseado em gradiente, proposto em Lucas e Kanade (1981), seguido pelo baseado em energia, proposto em Fleet e Jepson (1990).

Em Liu et al. (1998) são analisados algoritmos para estimação do fluxo óptico quanto à exatidão e eficiência para aplicação em tempo-real. Foram comparados os 
resultados obtidos para algoritmos baseados em gradiente e correspondência de blocos. Quanto à exatidão, Liu et al. (1998) usou os resultados apresentados em Barron et al. (1994). Quanto a relação tempo de execução e erro na estimação, o algoritmo proposto em Lucas e Kanade (1981) foi o que apresentou o melhor resultado. Foram testados os métodos Horn e Schunck (1981) apresentados na Seção 3.3.1.1, Lucas e Kanade (1981) apresentado na Seção 3.3.1.2, Anandan (1989) apresentado na Seção 3.3.2, Fleet e Jepson (1990) apresentado na Seção 3.3.3, além do método Uras et al. (1989).

Em Galvin et al. (1998) é comparado o desempenho de algoritmos para estimação do fluxo óptico quanto:

- ao erro angular: diferença entre o ângulo real e o estimado do vetor do fluxo óptico;

- à diferença de magnitude: diferença média entre a magnitude real e a estimada para cada pixel;

- ao erro normal: medida do erro na estimação dos vetores do fluxo óptico devido ao problema de abertura.

Em Galvin et al. (1998) também investigaram o desempenho de oito algoritmos para a estimação do fluxo óptico, seis dos quais já haviam sido testados em Barron et al. (1994). A diferença entre estes dois estudos, é que o de Galvin et al. (1998) utilizou imagens sintéticas mais complexas, adicionadas de ruídos.

Os algoritmos testados em Galvin et al. (1998) e descritos na Seção 3.2 foram os de: Horn e Schunck (1981), Lucas e Kanade (1981) e Anandan (1989). Além desses métodos, foram testados também: Uras et al. (1989), Proesmans et al. (1994), Uras et al. (1989), Nagel (1983), Singh (1990), Camus (1997).

Em suas conclusões, Galvin et al. afirma que o algoritmo de Lucas e Kanade (1981) tem o melhor desempenho, pois produz vetores de velocidade com boa precisão, a um baixo custo computacional e com boa tolerância a ruídos.

Esses três estudos, de maneira geral, podem ser resumidos na Tabela 3.1 e identificam o algoritmo proposto em Lucas e Kanade (1981) como o de melhor desempenho.

\subsection{Características físicas de pedestres}

O problema de contar o número de pessoas em uma seqüência imagens caracteriza-se como um exemplo dos casos particulares do problema mais geral da contagem 
Tabela 3.1: Comparação entre métodos para estimação do fluxo óptico.

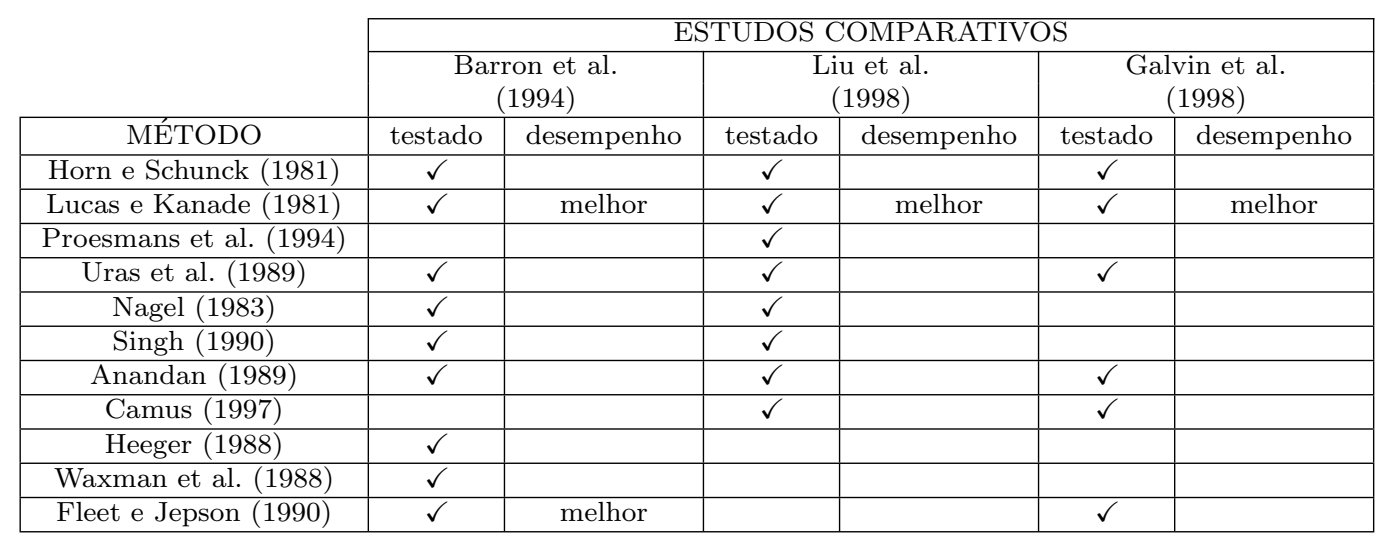

de objetos. Pessoas normalmente podem ter formas que variam (a altura, a largura e a cor). Essas podem ser vistas como pertencentes à classe complexa de objetos não rígidos. A utilização de diferentes roupas e acessórios, freqüentemente, faz com que a estrutura do corpo humano não seja bem definida. O somatório dos fatores mencionados contribui para dificultar a definição de um modelo robusto para pessoas em movimento. A fim de minimizar essas dificuldades, Pádua (2002), propõe que pedestres sejam considerados objetos rígidos com três características bem definidas:

- caminham com uma velocidade constante;

- têm uma profundidade;

- possuem uma largura.

Nas seções seguintes é apresentado um resumo dos estudos realizados para determinar os valores desses parâmetros.

\subsubsection{Dimensões humanas}

Dimensões humanas são freqüentemente utilizadas por designers em muitos campos, tais como na engenharia, na arquitetura e no desenho industrial. Em Diffrient et al. (1981) são encontradas informações sobre dimensões do corpo humano para homens, mulheres e crianças usadas como uma das referências para as áreas anteriormente citadas. Para o caso da largura entre os ombros, por exemplo, esse manual sugere os valores mostrados na Tabela 3.2.

Fruin (1971) sugere uma distância entre ombros entre 0,526m e 0,579m, e, para a profundidade do corpo, $0,330 \mathrm{~m}$. 
Tabela 3.2: Larguras entre ombros sugeridas em Diffrient et al. (1981).

\begin{tabular}{|c|c|c|c|}
\hline Dimensão $(\mathrm{m})$ & mínima & média & máxima \\
\hline largura entre ombros & 0,315 & 0,351 & 0,381 \\
\hline
\end{tabular}

Em Neufert (1976) são apresentadas medidas das dimensões do corpo humano que servem de referência para a construção de móveis, tais como cadeiras, mesas, camas, entre outros, bem como para a determinação da largura de corredores, portas, e inclusive para se determinar o lay-out desses móveis dentro de um espaço. As medidas sugeridas nessa referência são as seguintes: $0,5 \mathrm{~m}$ para a largura entre ombros de um homem adulto em pé e de $0,375 \mathrm{~m}$ para profundidade do tórax.

$\mathrm{Na}$ literatura pesquisada, os valores para a largura entre ombros encontrados para pedestres adultos em pé, variam de 0,315m (Diffrient et al., 1981) a 0,579m (Fruin, 1971). No projeto proposto será considerada a média aritmética entre esses valores, ou seja, 0,45m. Já para a profundidade do tórax os valores encontrados foram de 0,330m (Fruin, 1971) e 0,375m (Neufert, 1976). Assim será considerada a média aritmética entre esses dois valores, ou seja, $0,35 \mathrm{~m}$.

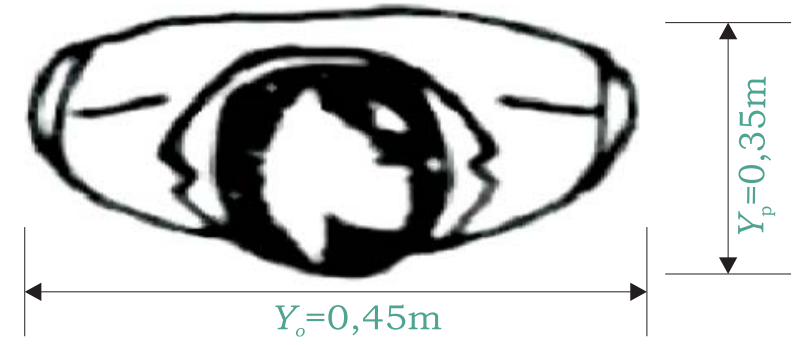

Figura 3.8: Visão do topo de uma pessoa em pé e as dimensões entre ombros, $Y_{o}$, e da profundidade do tórax, $Y_{p}$, que serão utilizados neste trabalho.

\subsubsection{Velocidade de pedestres}

Alguns estudos encontrados na literatura examinam a velocidade de pedestres sob as mais diferentes condições. Esses estudos podem ser encontrados em Finley e Cody (1970); Sammarco (1989); Ke-Okoro e Sandlund (1984); Knoblauch et al. (1996); HCM (2000).

Esses trabalhos mostram que vários fatores podem interferir na velocidade com a qual caminha um pedestre. Essa velocidade pode variar em função do gênero e idade do pedestre, do ambiente onde caminha, da carga que carrega, do calçado que usa e da direção na qual caminha. 
Em Ke-Okoro e Sandlund (1984) é apresentada uma pesquisa realizada com 527 pedestres caminhando por um espaço de 18 metros, em uma calçada, em ambiente urbano externo, nivelada, com idades que variavam entre 20 e 70 anos. Os resultados mostraram que o grupo de pessoas que caminhavam em direção à entrada de um shopping center apresentava velocidade significativamente mais alta do que o grupo em sentido contrário.

Em Finley e Cody (1970) é apresentada pesquisa com uma amostra de 1106 pedestres. Esses pedestres caminhavam em quatro locais distintos em ambientes urbanos: uma pequena área comercial, um shopping center, uma área no centro da cidade e uma área de uma região habitacional. Todos os registros foram feitos em função do gênero, direção, número de passos e tempo utilizado para caminhar por uma distância de 50ft, ou, 15,24m. Cada uma das variáveis coletadas foram comparadas entre pedestres homens e mulheres, e entre as quatro áreas. A investigação mostrou que os homens apresentaram uma velocidade superior à das mulheres. Os pedestres que caminhavam na área central da cidade possuíam uma velocidade maior que os pedestres das outras três áreas. O trabalho conclui que a velocidade dos pedestres altera-se e se ajusta às condições encontradas por esses.

Já em Knoblauch et al. (1996) é mostrado que pessoas mais velhas caminham mais lentamente do que as mais jovens, e que, assim como concluído em Finley e Cody (1970), mulheres caminham de maneira mais lenta que os homens. Knoblauch et al. (1996) sugere que pedestres adultos caminham com velocidades entre $1,253 \mathrm{~m} / \mathrm{s}$ e $1,501 \mathrm{~m} / \mathrm{s}$. Deve ser enfatizado que os valores encontrados em Knoblauch et al. (1996) foram obtidos para pedestres cruzando uma rua.

Em HCM (2000) sugere uma velocidade de 1,219m/s como uma velocidade normal para pedestres em áreas urbanas .

Já em Sammarco (1989), o andar normal é deslocar-se a uma velocidade de $5,63 \mathrm{~km} / \mathrm{h}$, ou $1,56 \mathrm{~m} / \mathrm{s}$.

Além dos fatores já citados, outros podem influenciar na velocidade dos pedestres tais como a inclinação do chão, densidade do fluxo de pedestres, uma carga, utilização de um objeto de apoio, como muletas ou cadeiras de roda.

\subsection{Considerações finais}

No Capítulo 3 foram apresentados estudos da literatura de fluxo óptico, de interesse para o projeto em questão, assim como estudo sobre dimensões humanas e velocidades de pedestres. 
A Seção 3.4, discutiu o desempenho dos método para estimação do fluxo óptico e dos estudos comparativos concluiu-se que o método proposto em Lucas e Kanade (1981) é o que apresenta o melhor desempenho entre os métodos descritos. Apesar de não ser o método de menor custo computacional, ele atende a um dos objetivos desse trabalho, que é a sua utilização em tempo real, além de apresentar exatidão adequada.

Na Seção 3.5 foram apresentados fatores humanos, tais como dimensões corporais e velocidade de pedestres. Para a velocidade o valor que será adotado nesse trabalho será de 1,56m/s (Sammarco, 1989), que é a maior das velocidades encontradas para pedestres, e portanto, representa o caso mais crítico, ou seja, aquele em que o pedestre caminha mais rapidamente. Já para as dimensões corporais humanas os valores que serão adotados como referência são de $0,45 \mathrm{~m}$ para a largura entre ombros e de 0,35m para a profundidade do tórax (Figura 3.8). 


\section{Capítulo 4}

\section{Descrição do sistema para a contagem de pedestres em fluxo multidirecional.}

\subsection{Considerações iniciais}

Nesse capítulo é apresentada a metodologia utilizada na estimação do fluxo multidirecional de pedestres baseada em câmeras de vídeo. Serão apresentadas as etapas estágios do algoritmo implementado para esta estimação e a metodologia utilizada na calibração do sistema.

\subsection{Visão geral do sistema proposto}

Na Figura 4.1 é apresentada uma visão geral do sistema utilizado para a contagem multidirecional de pedestres, a qual se baseia na análise de seqüências de imagens digitais.

Como mostrado na Figura 4.1, a primeira etapa consiste em capturar a seqüência de imagens em um ambiente que não restrinja a direção dos pedestres. Uma vez capturado pelo menos um par de frames consecutivos desta seqüência, a estimação do movimento é computada através do algoritmo proposto em Lucas e Kanade (1981), descrito na Seção 3.3.1.2, cujo código se encontra em Rittner (2004).

Após computado o campo de fluxo óptico, é executada uma análise espaçotemporal, para finalmente determinar o número de pedestres que cruzam a área monitorada pela câmera, bem como a estimação de suas direções. O algoritmo que foi desenvolvido para este fim pode ser dividido em 3 fases: 


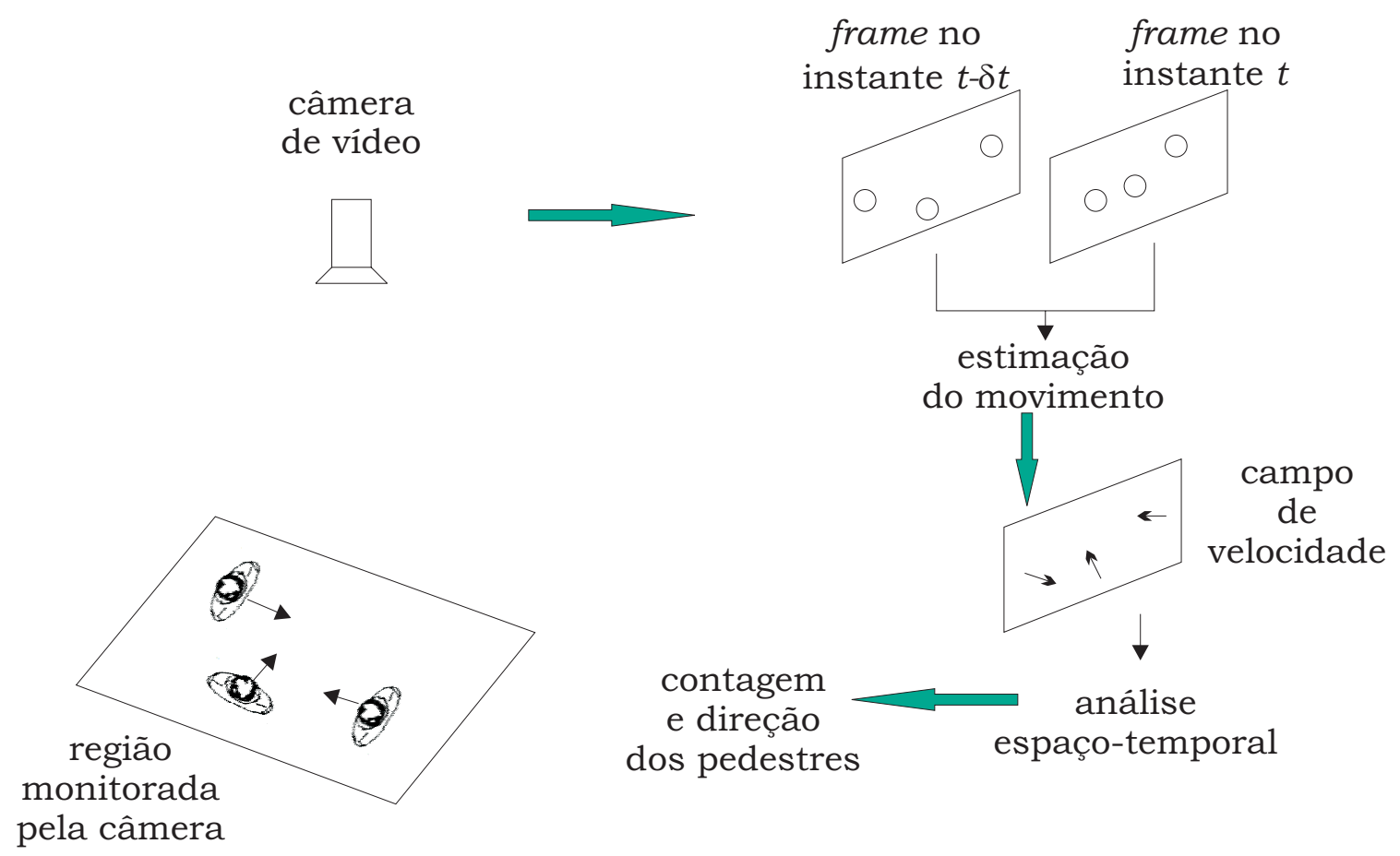

Figura 4.1: Visão geral do sistema proposto.

- fase 1 - somatório das componentes ortogonais dos vetores de velocidade;

- fase 2 - segmentação dos objetos que se movem pela cena;

- fase 3 - validação, incremento e estimação da direção dos pedestres na cena.

O sistema foi inicialmente calibrado e o procedimento de calibração, assim como, uma descrição mais detalhada das fases do algoritmo serão apresentados nos ítens seguintes.

\subsection{Captura da seqüência de imagens digitais}

Para a captura das seqüências das imagens, foi utilizada uma câmera de vídeo digital, do tipo WEBCAM, que foi instalada sobre a área a ser monitorada, de forma tal que seu eixo óptico estivesse ortogonal ao plano do chão, conforme ilustrado pela Figura 4.2. O posicionamento da câmera dessa forma tem por objetivo minimizar o problema de oclusão, problema este descrito na Seção 3.2. A altura da câmera em relação ao solo foi definida durante a fase de calibração do sistema.

A câmera foi conectada à porta USB de um computador do tipo PC. O uso de uma câmera digital permite que a seqüência de imagens seja transmitida ao 


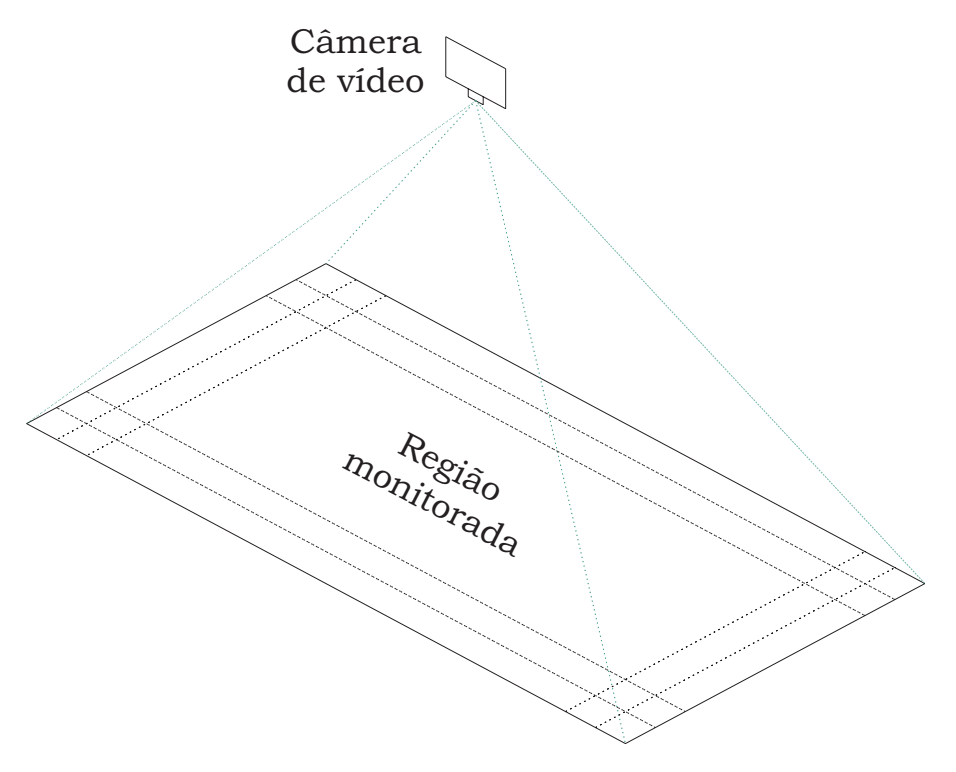

Figura 4.2: Posição da câmera de vídeo em relação ao chão.

computador já no formato digital, eliminando assim a necessidade de se utilizar uma placa digitalizadora e reduzindo assim o custo financeiro do projeto.

O formato dos arquivos das seqüencias de imagens capturadas é do tipo AVI, sem compactação, com resolução de 240x320 pixels com profundidade de 24 bits, e padrão RGB. Os arquivos foram armazenados e posteriormente processados em um computador do tipo PC, com processador Pentium IV de $3,2 \mathrm{MHz}$ e $512 \mathrm{MB}$ de memória principal, sobre o sistema operacional Windows XP Home.

\subsection{Estimação do fluxo multidirecional}

O fluxo multidirecional representa o caso mais complexo de fluxo de pedestres, no qual as pessoas entram e saem de uma área em qual direção. Supondo, por exemplo, o pedestre rotulado pelo número 1 na Figura 4.3. Esse pedestre está entrando na cena pela área 1 e poderá sair dela pelas áreas 1, 2, 3 ou 4. Este tipo de fluxo é mais comum em ambientes não restritos, sejam esses ambientes abertos ou fechados.

Para se estimar o fluxo multidirecional de pedestres em uma dada região, o que importa é o número total de pedestres que entram e saem da região monitorada, não sendo necessário a identificação de qual pedestre entrou ou saiu.

A Figura 4.4 ilustra que a região monitorada pela câmera de vídeo é dividida em quatro áreas: 1, 2, 3 e 4. Por sua vez, essas quatro áreas são sub-divididas em duas sub-áreas, utilizadas na identificação do sentido de movimento dos pedestres. 


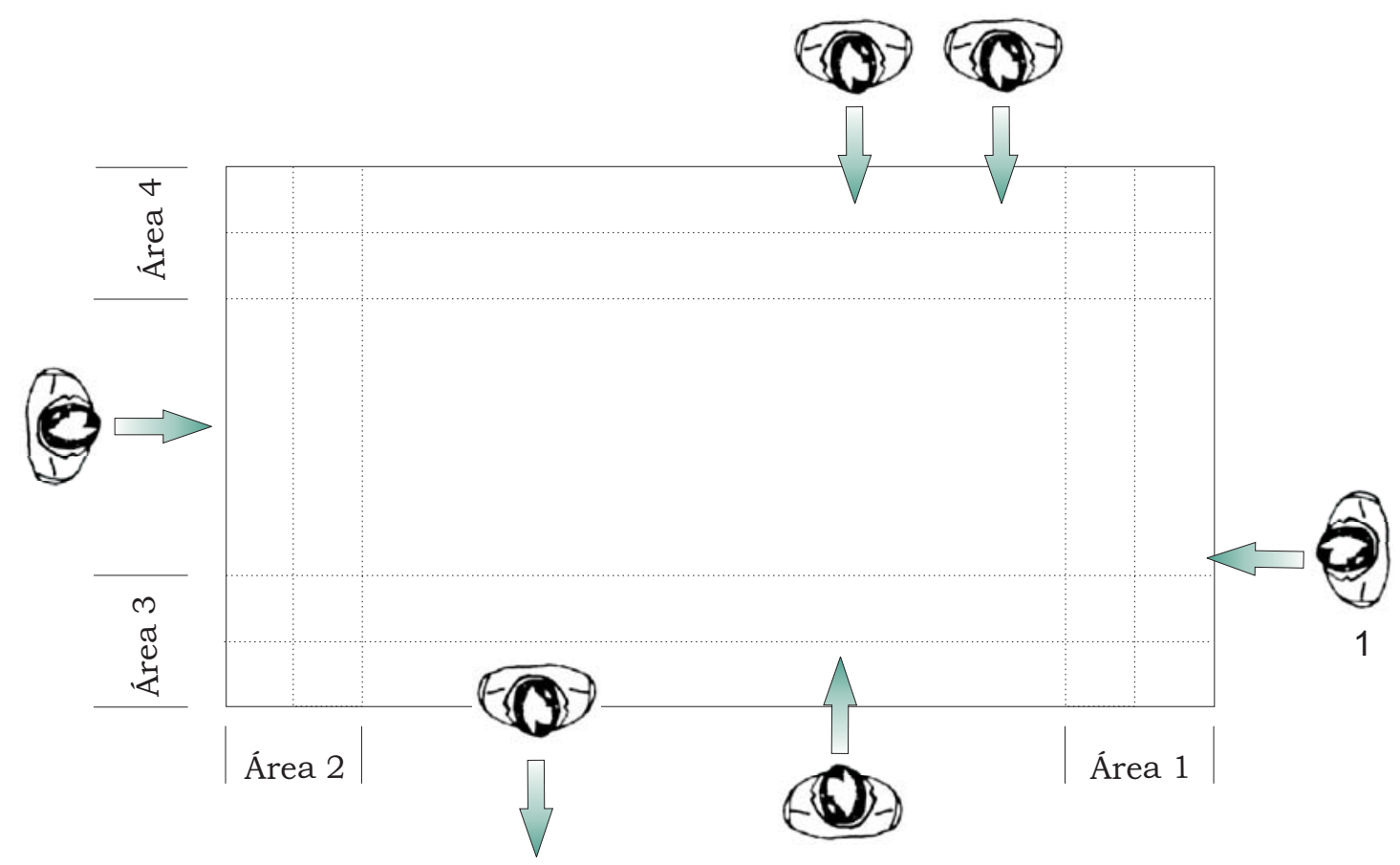

Figura 4.3: Fluxo multidirecional de pedestres: o pedestre rotulado pelo número 1 entra na região monitorada pela área 1 e pode sair por qualquer outra área.

A largura dessas sub-áreas é função do valor da profundidade do tórax do pedestre, $Y_{p}$, conforme apresentado na Seção 3.5.1 e ilustrado pela Figura 3.8.

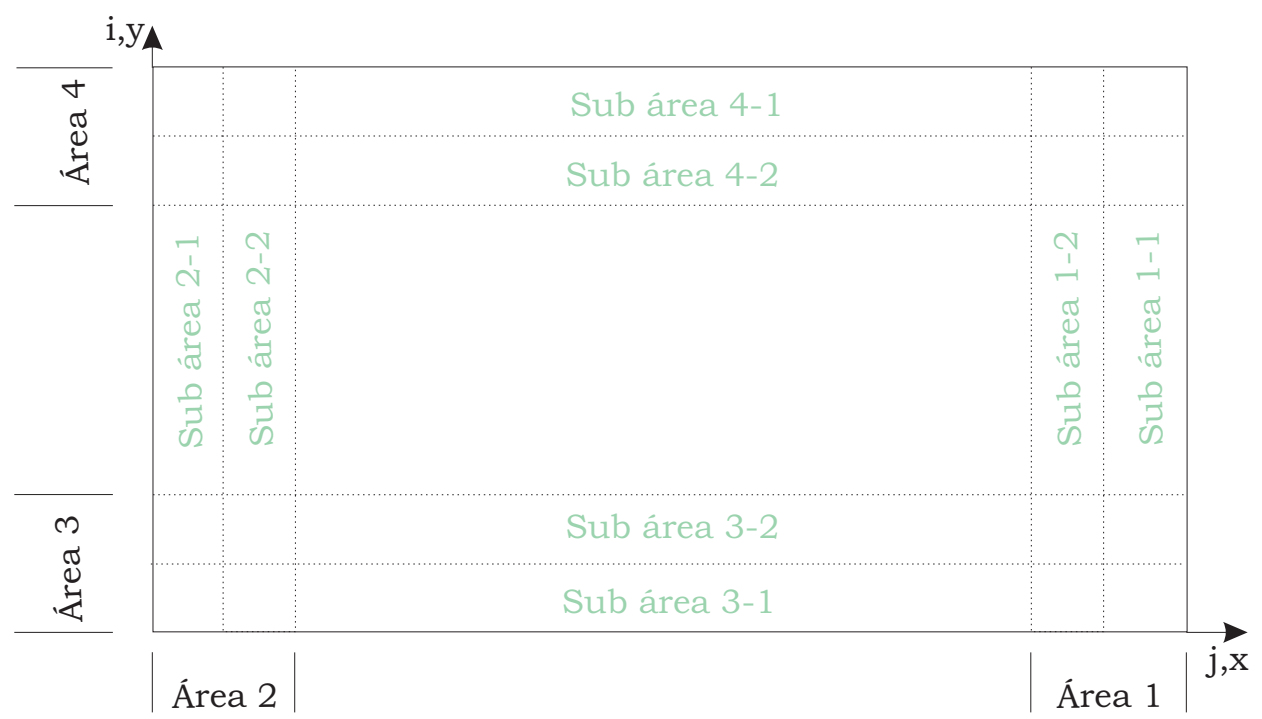

Figura 4.4: Divisão e sub-divisão da região monitorada pela câmera de vídeo.

O período de amostragem mínimo é determinado através das larguras das sub-área e das velocidades dos pedestres. Na Seções 3.5.1 e 3.5.2, foram discutidas e adotados, respectivamente, os valores de $0,35 \mathrm{~m}$ e $1,56 \mathrm{~m} / \mathrm{s}$ para a profundidade do tórax e velocidade média dos pedestres. 
O período de amostragem mínimo é dado pela Equação 4.1.

$$
T A=\frac{Y_{p}}{V P}
$$

Na Equação 4.1:

- $T A$ é o período de amostragem;

- $Y_{p}$ a profundidade do tórax;

- $V P$ a velocidade média dos pedestres.

Portanto, o período de amostragem é de $0,22 \mathrm{~s}$, sendo o valor adotado nos experimentos realizados o de $0,2 \mathrm{~s}$, ou $5 \mathrm{~Hz}$.

Esse período garante que um pedestre andando a uma velocidade de $1,5 \mathrm{~m} / \mathrm{s}$ no sentido $-y$ será detectado, por exemplo, na sub-área 3-2 no instante $t-\delta t$ e na sub-área 3-1 no instante $t$, como ilustrado pela Figura 4.5 (a).

Com períodos inferiores a $T A$ um pedestre que caminha com velocidade de 1,5m/s seria detectado na sub-área 3-1 mas não na sub-área 3-2, ou, vice-versa. Essa situação é ilustrada na Figura 4.5 (b) e 4.5 (c).

Essa situação gera um erro na estimação do número de pedestres que entram ou saem da região monitorada, já que a validação e incremento da contagem do número de pedestres, bem como a estimação de sua direção, tem como base a detecção de movimento em sub-áreas adjacentes em instantes de tempos consecutivos.

A direção do pedestre é estimada da seguinte forma:

- pedestres entrando na região monitorada, pela área 3: ativam primeiro a subárea 3-1 e na seqüência a sub-área 3-2;

- pedestres saindo na região monitorada, pela área 3: ativam primeiro a sub-área 3-2 e na seqüência a sub-área 3-1.

Uma sub-área é ativada quando a presença de um objeto em movimento é detectada.

Na Seção 4.4.3 será descrita detalhadamente a metodologia para a validação e incremento da contagem do número de pedestres, bem como para a estimação de sua direção. 
(a)
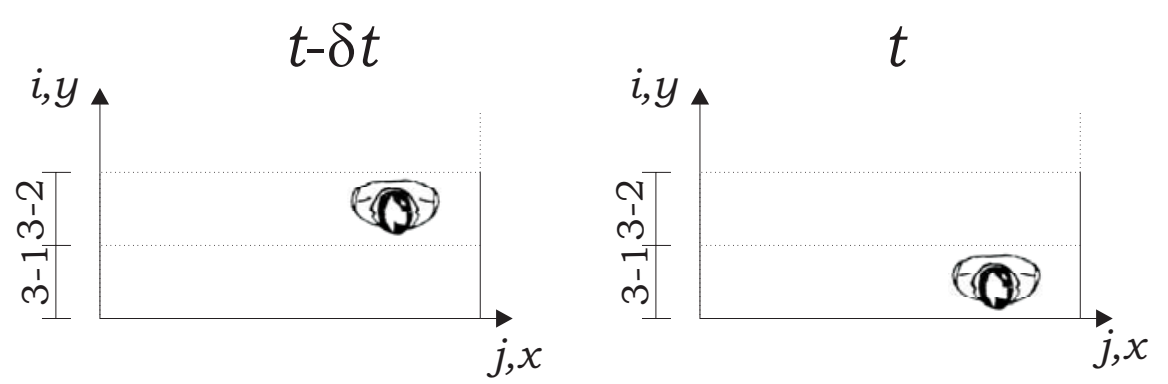

(b)
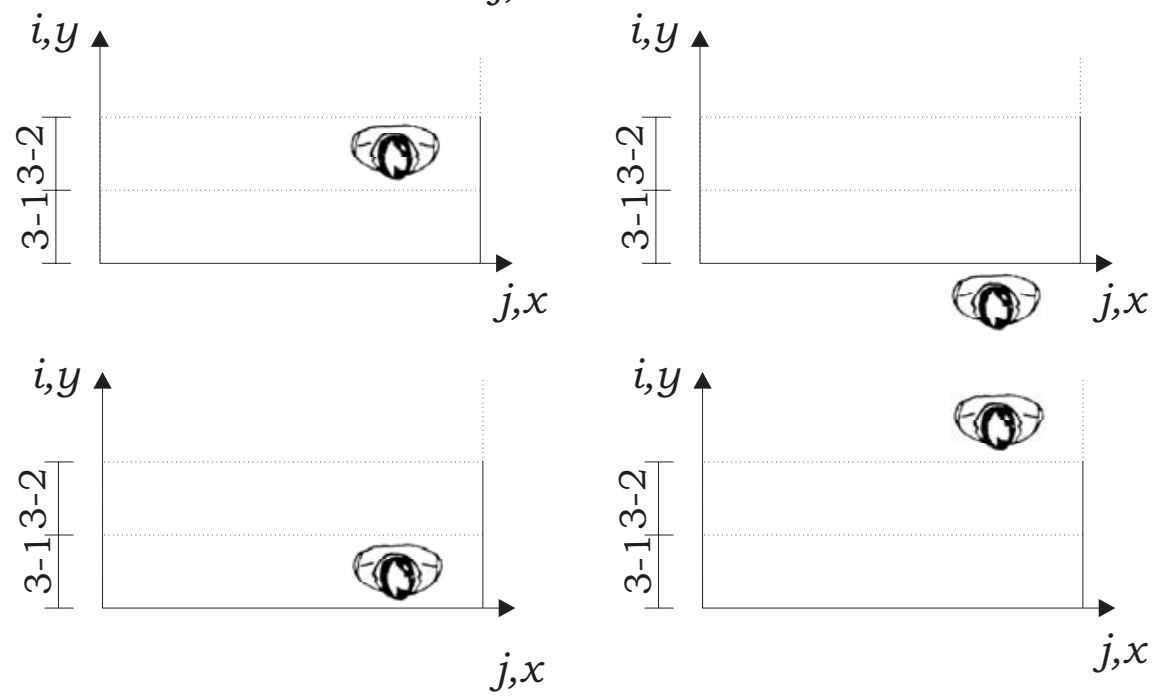

Figura 4.5: (a) Imagens capturadas com período igual a $T A$.(b) e (c) Imagens capturadas com períodos inferiores a $T A$.

\subsubsection{Somatório das componentes ortogonais dos vetores ve- locidade}

Após a aquisição de um par de frames da área monitorada e a determinação do campo do fluxo óptico, a primeira fase do algoritmo consiste no somatório das componentes do vetor velocidade nas oito sub-áreas.

A Figura 4.6 ilustra o caso de um único pedestre caminhando no sentido $-y$. Na Figura 4.6(a) ele está entrando na sub-área 3-2 no instante de tempo $t-\delta t$, e, na Figura 4.6(b) ele está na sub-área 3-2, no instante t. O campo de movimento, calculado a partir deste par de imagens, gera para cada pixel, o vetor velocidade $v$, com componentes ortogonais $u$ e $r$.

Os objetos em movimento na cena são detectados através do valor do módulo das componentes ortogonais de $v$, ou seja, se $|u| \neq 0$ ou $|r| \neq 0$, há movimento na cena 3D, movimento este causado por um objeto.

Para objetos que se movimentam predominantemente na direção do eixo $x$, espera-se que a componente $|u|$ tenha valor maior que o da componentes $|r|$, e que para movimentos de pedestres onde a direção paralela ao eixo y predomina, que a 
(a)

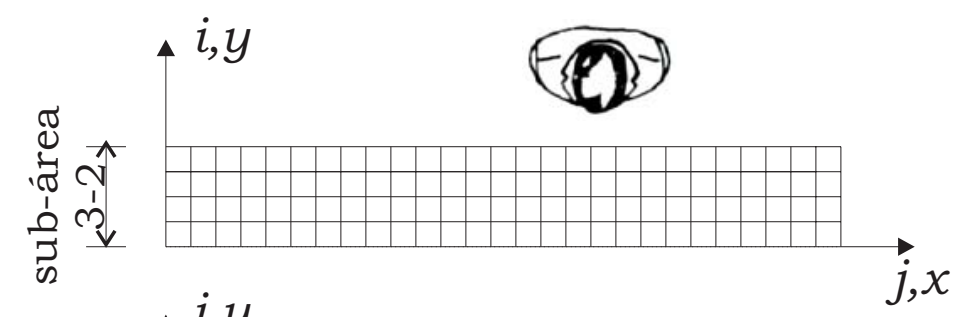

(b)

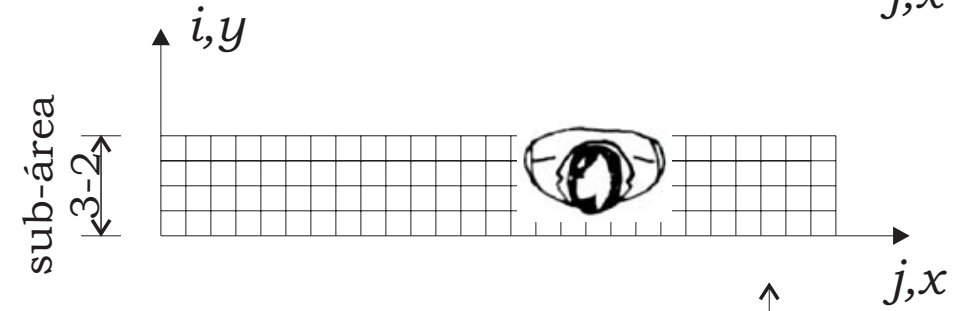

(c)

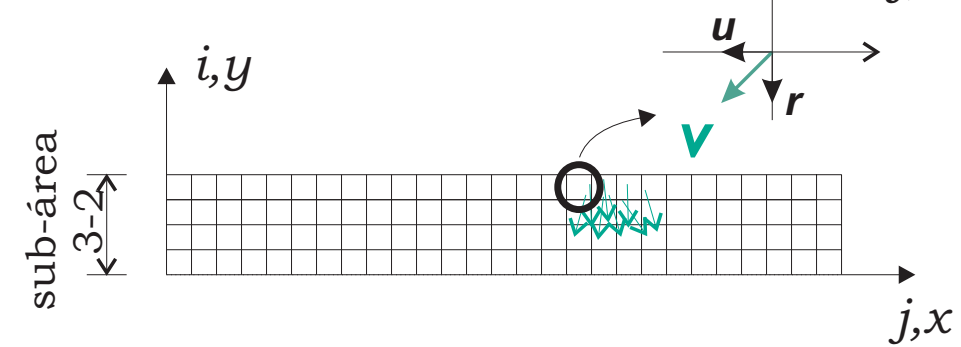

Figura 4.6: Único pedestre cruzando a sub-área 3-2 em dois instantes de tempo: (a) $t-\delta t$ e (b) $t$; e (c) vetores $v$ do campo de fluxo óptico gerados no instante $t$ devido ao movimento deste pedestre, bem como suas componente ortogonais $u$ e $r$.

componente $|r|$ tenha valor maior que o da componente $|u|$.

- sentido de movimento paralelo ao eixo $x:|u|>|r|$;

- sentido de movimento paralelo ao eixo $y:|r|>|u|$.

Neste trabalho, a identificação da presença de um objeto que esteja se movendo pela cena e sua identificação como sendo um pedestre, consiste primeiramente em definir valores de velocidades resultantes para cada linha das sub-áreas das áreas 1 e 2 e para cada coluna das sub-áreas das áreas 3 e 4.

Supondo, por exemplo, o caso ilustrado na Figura 4.6, onde um único pedestre está saindo da região monitorada pela câmera de vídeo pela sub-área 3-2. Para cada coluna $j$ do campo de velocidades referente à sub-área 3-2, define-se o módulo da velocidade resultante $S_{32}$, pela Equação 4.2 .

$$
\left|S_{32(j, t)}\right|=\sum_{i=I-2 f+1}^{I-f}\left|r_{(i, j, t)}\right|
$$

Na Equação 4.2: 
- I representa o número de pixels presente no comprimento do frame;

- $f$ representa o número de pixels presente na largura da sub-área 3-2. Esse valor é determinado na fase de calibração do sistema, descrito na Seção 4.5, e está relacionado com o valor profundiade do tórax dos pedestres, $Y_{p}$, discutido na Seção 3.5.1 e ilustrado na Figura 3.8.

A velocidade $\left|S_{32(j, t)}\right|$ pode ser vista sob a forma de gráfico, conforme ilustrado pela Figura 4.7.

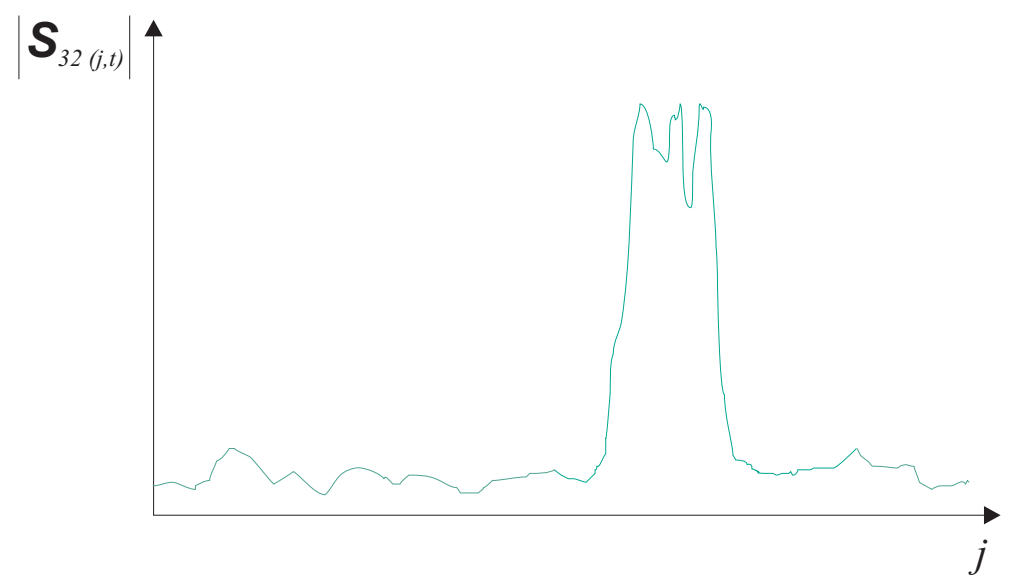

Figura 4.7: Somatório da componente $|r|$ do vetor velocidade $v$ na sub-área 3-2, em todas as colunas.

\subsubsection{Segmentação dos objetos que se movem pela cena}

Dois limiares, Tmax e Tmin são utilizados para uma segmentação mais precisa dos objetos que se movem na região monitorada. A definição de dois limiares está vinculada à adoção de uma abordagem baseada em Curvas de Histerese, o que confere ao sistema maior confiabilidade no processo de segmentação de cada pessoa. Os valores desses limiares são definidos na fase de calibração do sistema e são funções diretas da taxa de frames por segundo e da largura das sub-áreas.

A utilização desses limiares gera uma nova função, $P$, como ilustrado na Figura 4.8, no formato de um ou mais pulsos, onde cada pulso corresponde a objetos que estejam em movimento nas áreas monitoradas.

A Figura 4.9 ilustra um pulso $P$ gerado, com largura $b$ e ponto médio $P m$. A largura deste pulso está relacionada com a largura dos objetos em movimento que gerou esses pulsos.

A largura desse pulso é utilizada para distinguir: 


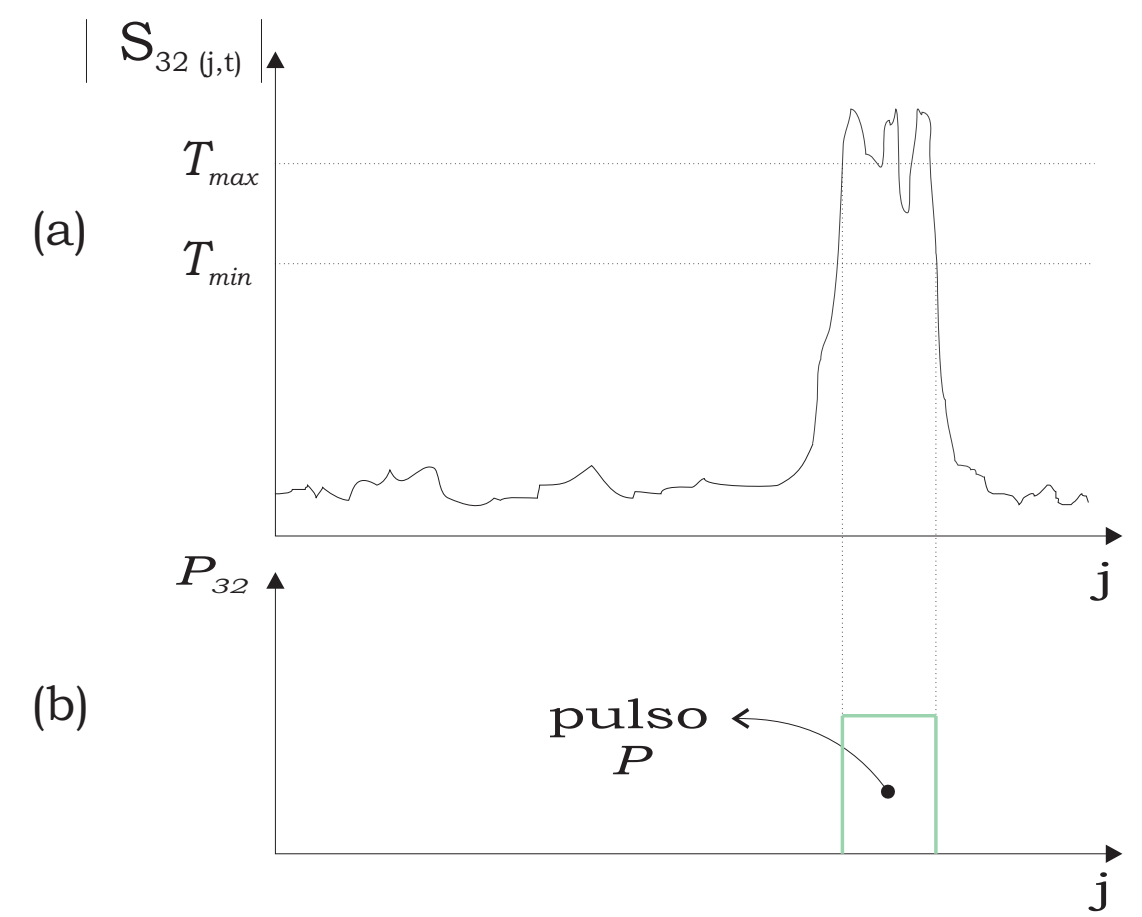

Figura 4.8: (a) Gráfico do somatório da componente $|r|$ do vetor velocidade $v$ na sub-área 3-2 no instante $t$ e os limiares Tmax e Tmin. (b) Pulso $P_{32}$ gerado na subárea 3-2, devido à presença de um objeto em movimento nessa sub-área no instante $t$.

- pedestres de outros objetos que se movem nas áreas monitoradas;

- pedestre que caminham muito próximos, lado a lado.

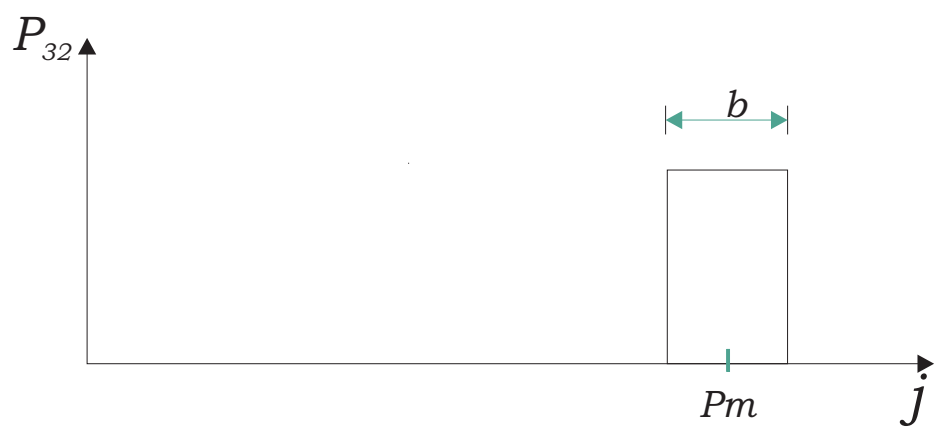

Figura 4.9: Pulso $P$ gerado por um objeto em movimento na sub-área 3-2, com largura $b$ e ponto médio $P m$. 


\subsubsection{Validação, contagem e estimação da direção dos pedestres na região monitorada}

O ponto médio $P_{m}$, ilustrado pela Figura 4.9, é utilizado em conjunto com a largura $b$ do pulso $P$ para validar como pedestre, o objeto que se move pela região monitorada.

A estimação do número de pedestres que trafegam pela área monitorada é obtida não só através de uma análise espacial, mas também, através de uma análise temporal dos pulsos $P$.

Nesse contexto, uma mapa espaço-temporal dos pulsos $P$ deve ser definido e constantemente analisado pelo sistema. Esse mapa contém os pulsos $P$, gerados pelos pedestres que se movem pela cena, nos instantes de tempo $t-\delta t$ e $t$.

A Figura 4.10 ilustra a movimentação de três pedestres rotulados com os números 1,2 e 3 , nos instantes de tempo $t_{0}, t_{1}, t_{2}$ e $t_{3}$, sendo $t_{3}>t_{2}>t_{1}>t_{0}$. Os pedestres 1 e 2 estão entrando na região monitorada pela câmera de vídeo pela área 3 e o pedestres rotulado com o número 3 está saindo da região monitorada pela mesma área.

A Figura 4.10 evidencia que para os pedestres rotulados pelo número 1 e 2, no instante $t-\delta t$, existirá um pulso $P$ na sub-área $3-1$ e no instante $t$ um outro pulso $P$ aparecerá na sub-área $3-2$, relativo aos mesmos pedestres 1 e 2 , para um período de amostragem $T A$.

Porém, como o corpo humano não é um objeto rígido, e suas partes podem apresentar diferentes velocidades em um mesmo instante de tempo, a largura dos pulsos $P$ podem não apresentar o mesmo valor em instantes de tempos consecutivos, bem como seus pontos médios, conforme ilustrado na Figura 4.11.

Na Figura 4.11(b) é ilustrado um pulso no instante $t-\delta t$ com largura $b_{0}$ e o ponto médio $P m_{0}$, e, na Figura 4.11(a), um pulso no instante $t$ com largura $b_{1}$ e o ponto médio $P m_{1}$. Esses pulsos serão considerados com sendo dos mesmos pedestres, caminhando lado-a-lado, se $\left|b_{0}-b_{1}\right|<\sigma,\left|P m_{0}-P m_{1}\right|<\xi$ e $\left|b_{0}+b_{1}\right| / 2$ for maior que o pulso de referência. Nessa situação, a contagem dos pedestres que entram da região monitorada pela câmera de vídeo será incrementada.

Os valores de $\sigma$ e $\xi$ foram definidos, durante o processamento das seqüências de imagens, pela análise dos pulsos $P$. 
(a)
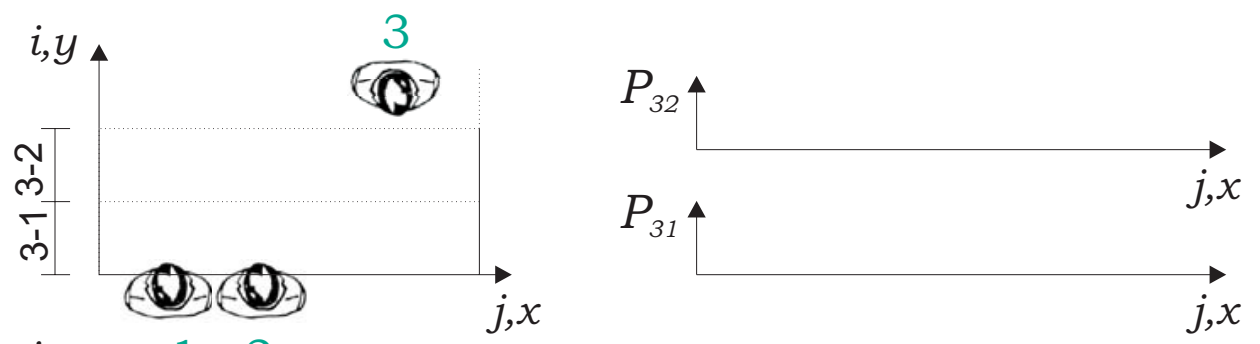

(b)
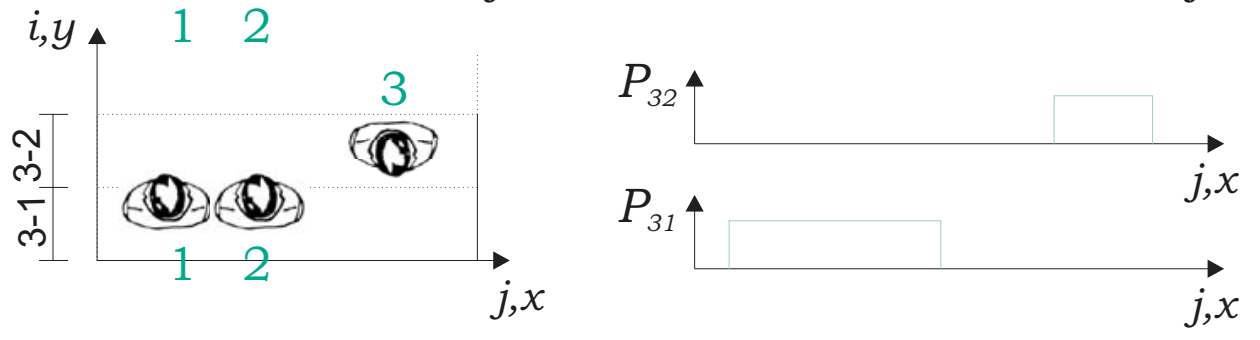

(c)
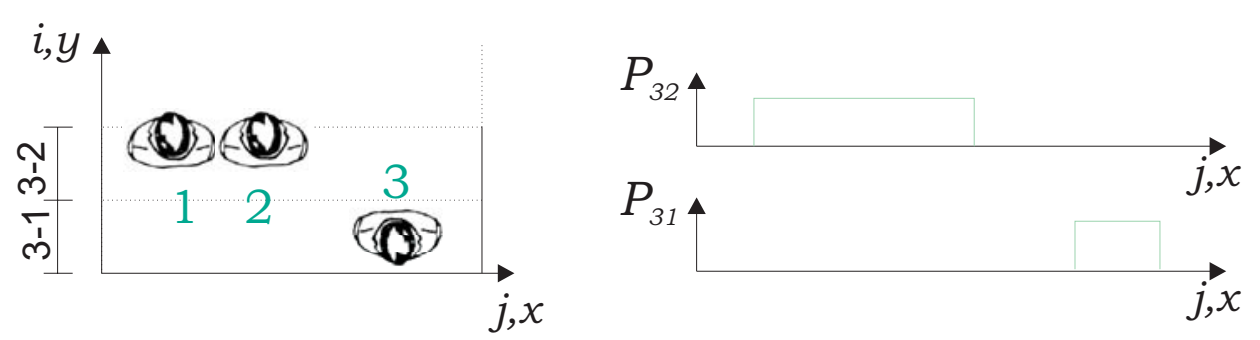

(d)
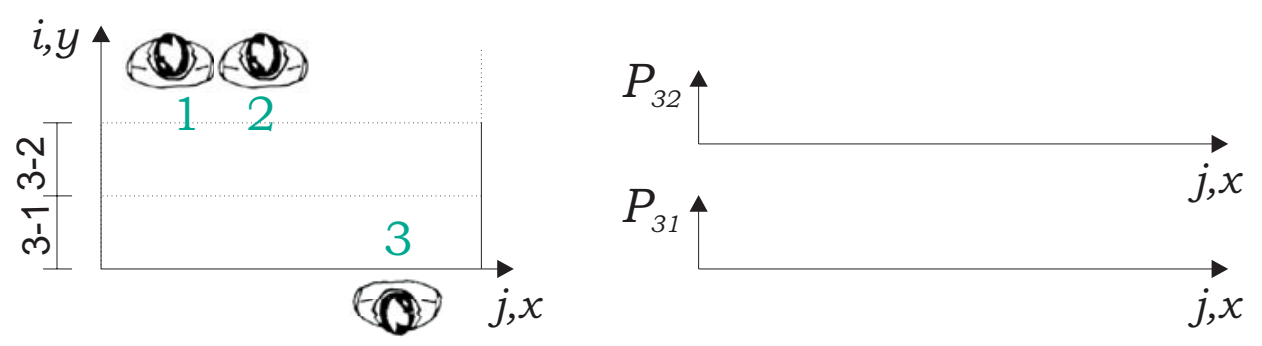

Figura 4.10: Três pedestres cruzando a área 3 nos instantes de tempo (a) $t_{0}$, (b) $t_{1}$, (c) $t_{2}$ e (d) $t_{3}$, sendo $t_{3}>t_{2}>t_{1}>t_{0}$, com pedestres 1 e 2 caminhando no sentido positivo do eixo $y$ e o pedestre 3 no sentido negativo de $y$, e os respectivos pulsos $P_{31}$ e $P_{32}$ gerados pelo movimento desses pedestres nas sub-áreas 3-1 e 3-2, para um período de amostragem $T A$

\subsection{Calibração do sistema}

O sistema deve passar por uma fase de calibração, que deve ser realizada antes do processamento das seqüencias de imagens. Na calibração os seguintes parâmetros são definidos:

- comprimento focal da câmera de vídeo;

- largura das sub-áreas;

- largura do pulso $P$ de referência;

- os limiares Tmax e Tmin. 
(a)

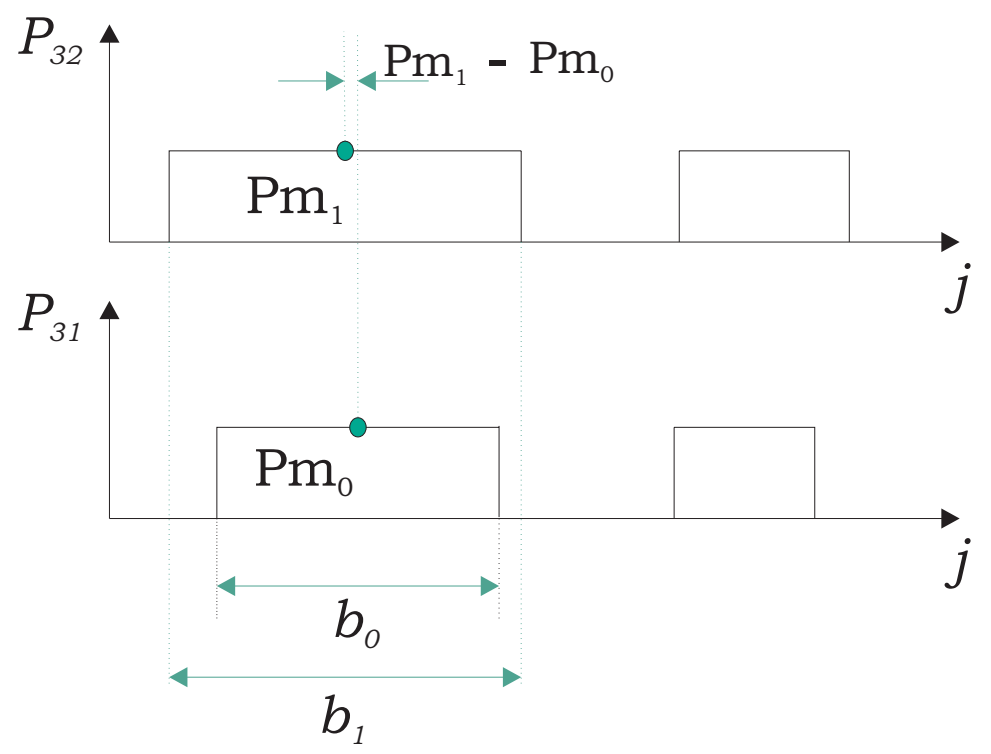

Figura 4.11: (a) Pulso no instante $t$ com largura $b_{1}$ e o ponto médio $P m_{1}$, na suaárea 3-2. (b) Pulso no instante $t-\delta t$ com largura $b_{0}$ e o ponto médio $P m_{0}$, na sub-área 3-1.

Para a determinação do comprimento focal da câmera de vídeo, foi utilizada a projeção perspectiva do objeto de calibração com dimensões conhecidas, como ilustrado pela Figura 4.12.

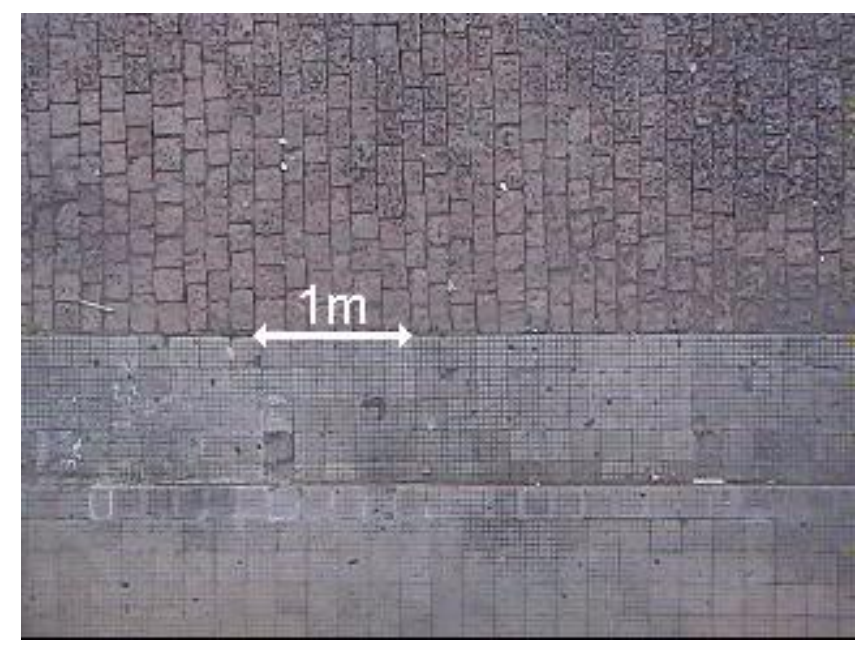

Figura 4.12: Calibração do sistema: um objeto de calibração de 1,0 metro, para a câmera de vídeo colocada a 7,6m, tem um comprimento de 60 pixels.

O comprimento focal da câmera de vídeo pode ser definido pela Equação 4.3.

$$
c_{f}=\frac{M_{p i} \cdot h_{c a m}}{M_{o c}}
$$

Na Equação 4.3: 
- $M_{o c}$ é o comprimento real do objeto de calibração em metros;

- $M_{p i}$ é o comprimento da marca em pixels no plano de imagem referente ao objeto de calibração;

- $h_{c a m}$ é a altura da câmera em relação ao chão.

Um vez determinado o comprimento focal da câmera de vídeo, as larguras das sub-áreas podem ser determinadas usando-se a projeção perspectiva da profundidade do corpo, $Y_{p}$, de uma pessoa, como ilustrado na Figura 4.13, de acordo com a Equação 4.4 .

$$
y_{p}=\frac{c_{f} \cdot Y_{p}}{h_{2}}
$$

Já a largura do pulso $P$, de referência, é dada pela Equação 4.5

$$
y_{o}=\frac{c_{f} \cdot Y_{o}}{h_{2}}
$$

Nas Equações 4.4 e 4.5:

- $Y_{o}$ - largura do ombro de uma pessoa no plano 3D;

- $Y_{p}$ - profundidade do tórax de uma pessoa no plano 3D;

- $y_{o}$ - largura do ombro de uma pessoa no plano de imagem, ou, pulso $P$ de referência;

- $y_{p}$ - profundidade do tórax de uma pessoa no plano de imagem;

- $h 2$ - diferença entre a altura da câmera de vídeo, relativamente ao chão, e a altura máxima de uma pessoa. Para a altura dos pedestres, o valor utilizado durante o processamento das seqüências de imagens foi de $1,85 \mathrm{~m}$, valor este do pedestres mais alto utilizado como ator durante a captura das seqüências de vídeo.

Os valores para a largura do ombro e profundidade do tórax, no plano 3D, foram discutidos e apresentados na Seção 3.5.

Os valores para Tmax e Tmin são definidos empiricamente, pela análise das curvas obtidas dos somatórios das componentes de velocidades. 

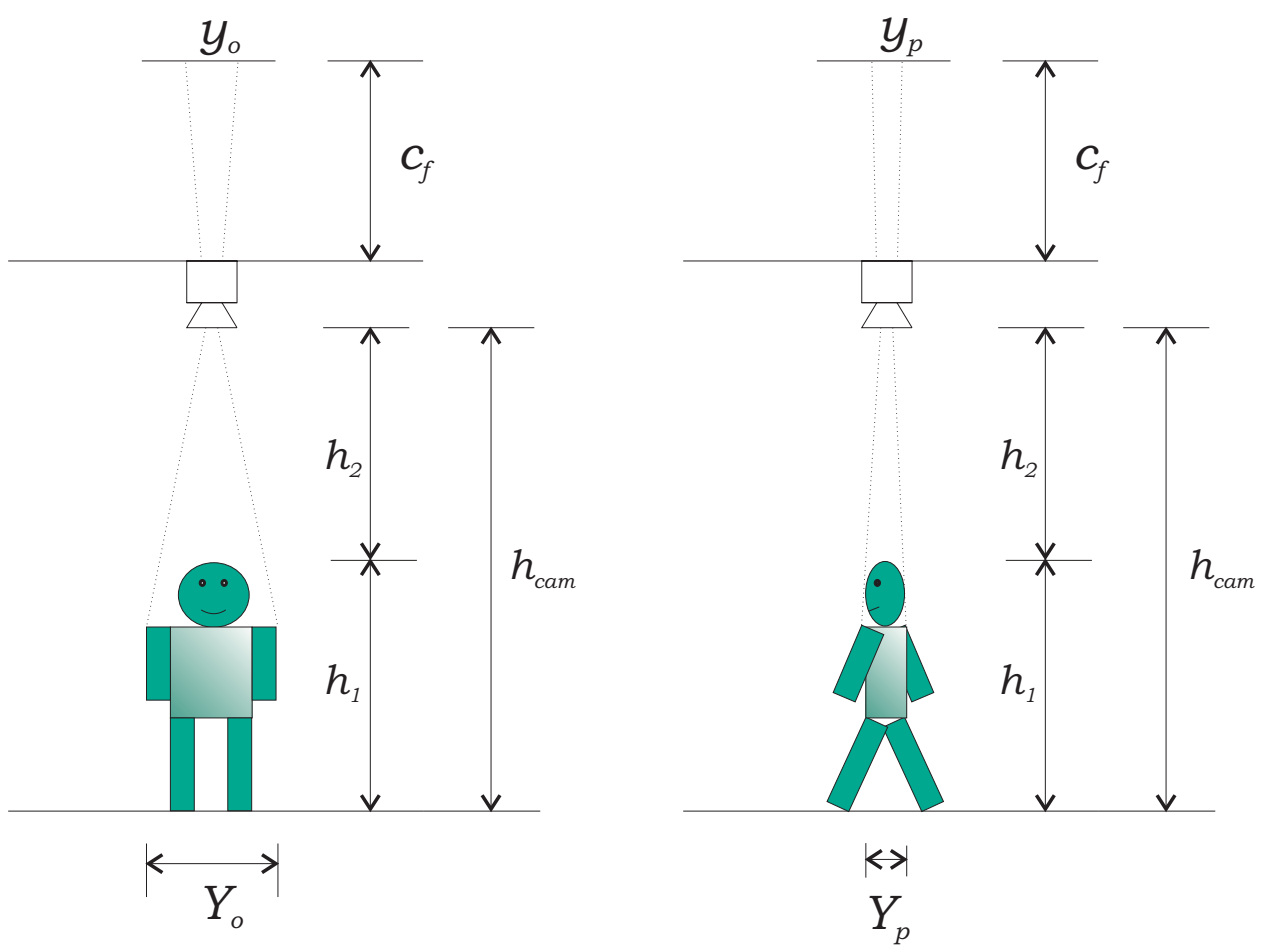

Figura 4.13: Projeção perspectiva das dimensões corporais $Y_{o}$ e $Y_{p}$ e de suas respectivas projeções no plano de imagem, $y_{o}$ e $y_{p}$.

\subsection{Considerações finais}

Neste capítulo foi descrito o sistema utilizado para a estimação do fluxo multidirecional de pedestres.

As etapas a serem seguidas para a estimação do fluxo de pedestres são as seguintes:

1. calibração;

2. captura dos frames;

3. estimação do fluxo óptico;

4. e a aplicação das três fases do algoritmo. 


\section{Capítulo 5}

\section{Aquisição, processamento dos dados e análise dos resultados}

\subsection{Considerações iniciais}

Neste capítulo são descritos os experimentos executados, os resultados obtidos e a análise dos mesmos.

\subsection{Aquisição das seqüências de imagens}

A metodologia apresentada no Capítulo 4 foi aplicada às seqüências de imagens, obtidas com dois modelos diferentes de câmeras digitais do tipo WEBCAM, ilustradas na Figuras 5.1 e 5.2. Seus modelos são os seguintes:

- Panasonic, modelo miniDV PV-GS12;

- Aiptek, modelo DV 3100.

As duas câmeras capturam imagens com resolução de 240x320 pixels, com profundidade de 8 bits para cada cor, padrão RGB. Como já mencionado anteriormente, as imagens são armazenadas em arquivos, no formato AVI. No processamento dessas sequiências de vídeo, a resolução foi mantida, porém o padrão RGB foi convertido para níveis de cinza com 8 bits de profundidade.

Apesar das características similares, a câmera Panasonic gera imagens com qualidade superior à Aiptek.

A câmera de vídeo foi fixada em uma haste de metal, como ilustrado pela Figura 5.3, e instalada a uma altura aproximada de 7,6m. Por estar instalada em 


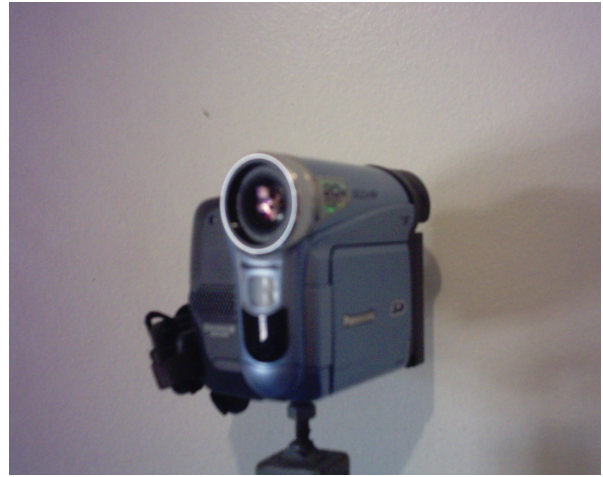

Figura 5.1: Câmera de vídeo digital Panasonic, modelo miniDV PV-GS12.

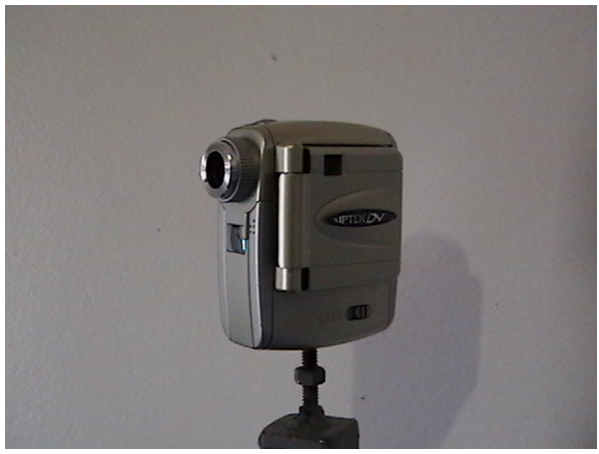

Figura 5.2: Câmera de vídeo digital Aiptek, modelo DV 3100.

uma região aberta, e ao ar livre, durante a captura das seqüências de imagens, as mesmas ficaram sujeitas a variações de iluminação e ação do vento.
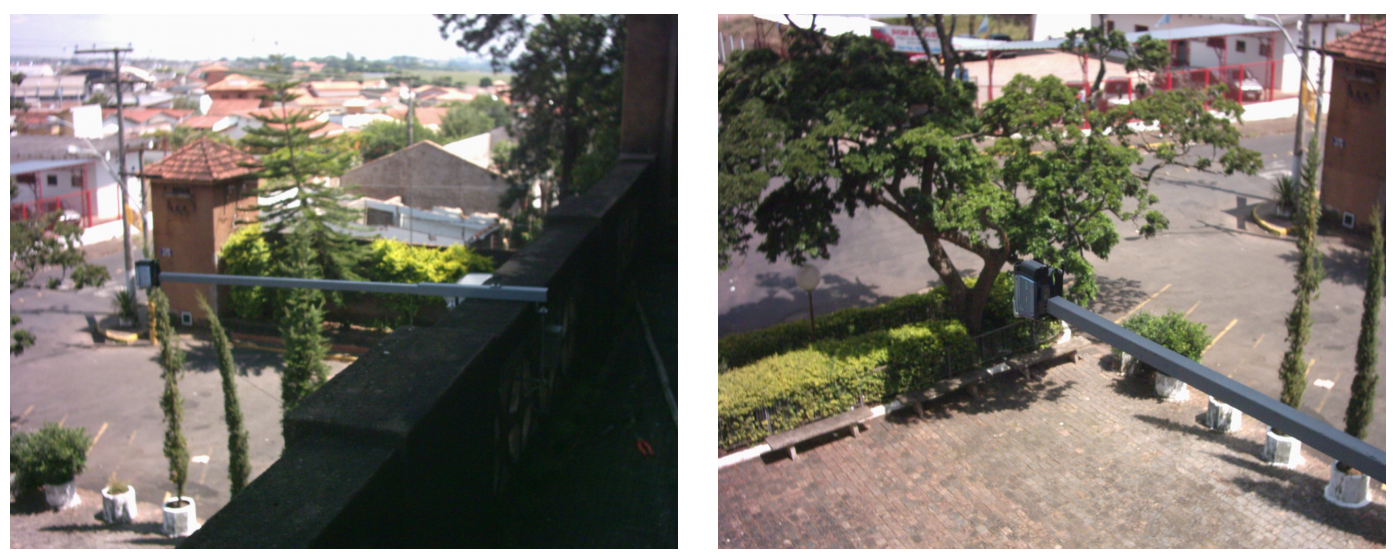

Figura 5.3: Posição da câmera vista por dois ângulos diferentes.

A região escolhida, por ser não restrita, permite que os pedestres caminhem em qualquer direção. A Figura 5.4 ilustra esta região vista de cima.

Foram capturadas oito seqüências de imagens, com aproximadamente 90 segundos cada seqüência, gerando um total de quatro arquivos para cada uma das câmeras de vídeo.

Durante a captura das seqüências cinco atores foram utilizados como pedestres, que caminharam constantemente na região monitorada. Esses atores possuem dimensões corporais diferentes, no que diz respeito a largura dos ombros, profundidade do tórax e altura, e trajavam roupas com cores diferentes, não utilizando porém, quaisquer acessórios tais como bolsas ou chapéus.

Para cada uma das quatro seqüências, e para cada câmera, os pedestres caminharam em direções determinadas, como segue: 


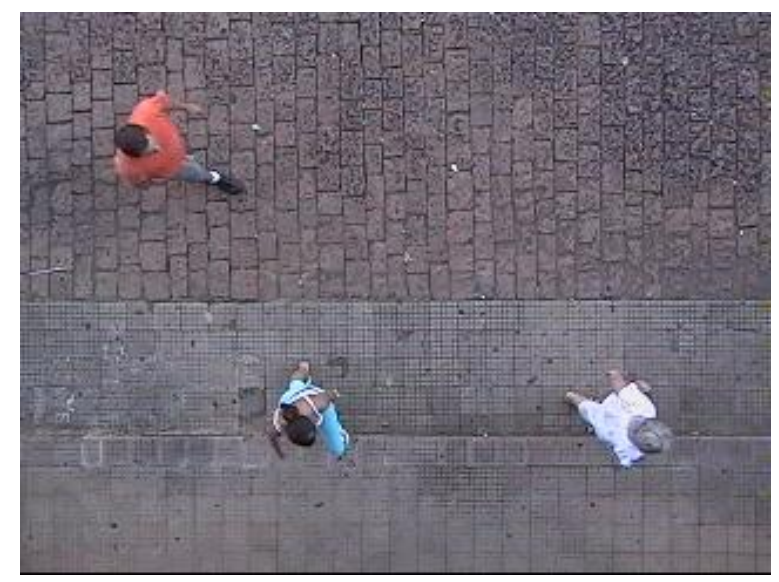

Figura 5.4: Região monitorada pela câmera.

- seqüência 1: direção $x$ ou $y$, predominantemente, sozinhos (Figura 5.5);

- seqüência 2: direção $x$ ou $y$, predominantemente, dois pedestres, lado-a-lado (Figura 5.6);

- seqüência 3: diagonalmente, sem impor restrições ao ângulo de entrada, sozinhos (Figura 5.7);

- seqüência 4: livremente em qualquer direção.
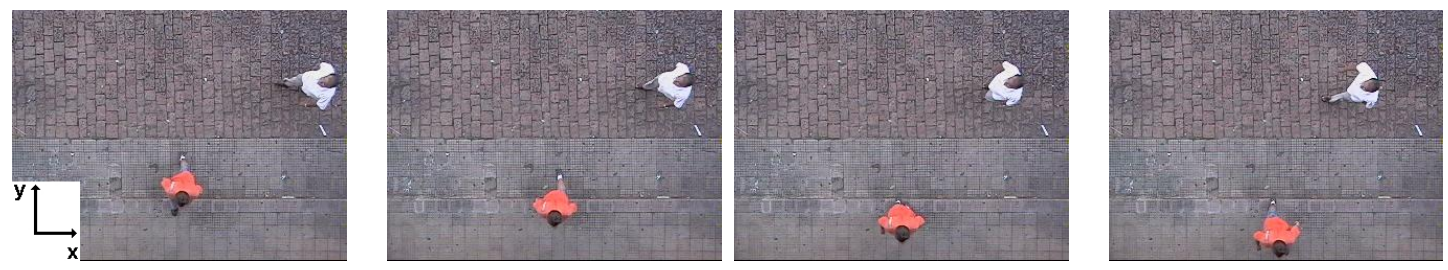

Figura 5.5: Sequiência de imagens 1 - pedestres caminham predominantemente nas direções $x$ ou $y$.
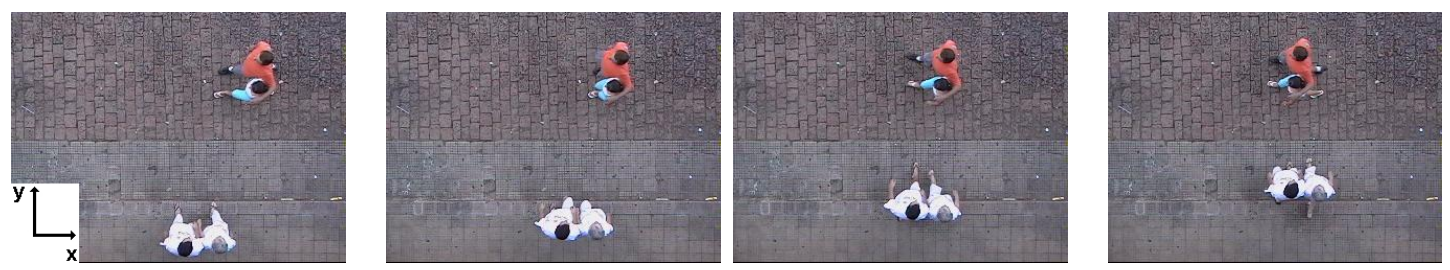

Figura 5.6: Seqüência de imagens 2 - pedestres caminham predominantemente nas direções dos eixos $x$ ou $y$, lado-a-lado, aos pares. 

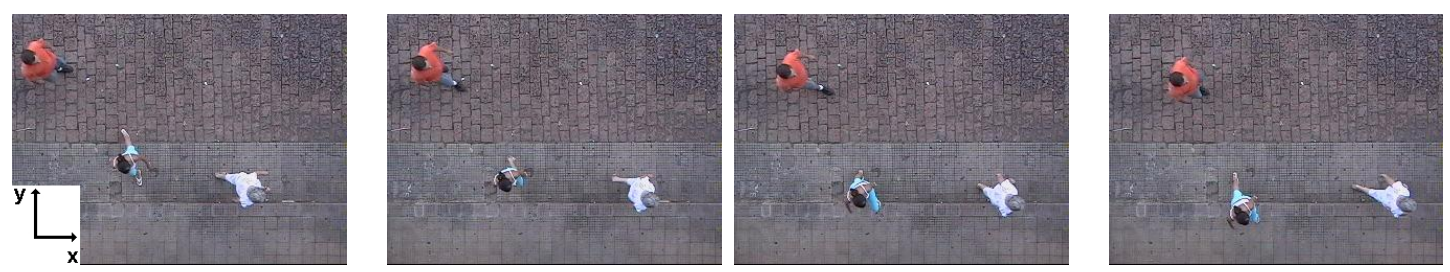

Figura 5.7: Seqüência de imagens 3 - pedestres caminham predominantemente em direções diagonais.

\subsection{Resultados obtidos}

Os resultados para cada seqüência são apresentados nas Tabelas 5.1 e 5.2.

Tabela 5.1: Resultados nas quatro seqüências obtidas pela câmera Panasonic.

\begin{tabular}{|l|c|c|c|}
\cline { 2 - 4 } \multicolumn{1}{c|}{} & \multicolumn{3}{c|}{ Câmera Panasonic } \\
\cline { 2 - 4 } \multicolumn{1}{c|}{} & Número real & Erros & $\%$ erro \\
\hline Seqüência 1 & 72 & 16 & 22,2 \\
\hline Seqüência 2 & 88 & 19 & 21,6 \\
\hline Seqüência 3 & 68 & 20 & 29,4 \\
\hline Seqüência 4 & 79 & 18 & 22,8 \\
\hline
\end{tabular}

Tabela 5.2: Resultados nas quatro seqüências obtidas pela câmera Aiptek.

\begin{tabular}{|c|c|c|c|}
\cline { 2 - 4 } \multicolumn{1}{c|}{} & \multicolumn{3}{c|}{ Câmera Aiptek } \\
\cline { 2 - 4 } \multicolumn{1}{c|}{} & Número real & Erro & $\%$ erro \\
\hline Seqüência 1 & 100 & 23 & 23,0 \\
\hline Seqüência 2 & 84 & 24 & 28,6 \\
\hline Seqüência 3 & 83 & 28 & 33,7 \\
\hline Seqüência 4 & 107 & 32 & 29,9 \\
\hline
\end{tabular}

O número real de pedestres que cruzam a área monitorada pelo sistema, bem como suas direções, foram obtidas visualmente, durante o processamento.

Nessas tabelas, a coluna "Número real", representa a quantidade de entradas e saídas de pedestres, da região monitorada, avaliada visualmente para cada seqüência. A coluna "Erros"representa o erro obtido na estimação do fluxo multidirecional dos pedestres pelo algoritmo desenvolvido.

A Tabela 5.3 ilustra a quantidade de entradas e saídas de pedestres das quatro seqüências para cada câmera e a respectiva porcentagem de erro obtida.

Durante a análise das seqüências foram considerados erros as seguintes situações: 
- pedestres que entravam ou saíam da região monitorada e não foram contados, $\mathrm{ou}$;

- pedestres que entravam ou saíam da região monitorada e foram contados mais de uma vez.

Tabela 5.3: Resultados globais para as duas câmeras.

\begin{tabular}{|r|c|c|c|}
\cline { 2 - 4 } \multicolumn{1}{c|}{} & Número real & Erro & $\%$ erro \\
\hline Panasonic & 307 & 73 & 23,7 \\
\hline Aiptek & 374 & 107 & 28,6 \\
\hline
\end{tabular}

Na próxima seção serão analisados os resultados obtidos na estimação do fluxo de pedestres.

\subsection{Análise dos resultados obtidos}

A análise dos resultados obtidos será feita considerando:

- resultados de trabalhos similares mencionados na Seção 2.3;

- a câmera utilizada: será feita comparação dos resultados globais obtidos para as duas câmeras;

- as seqüências obtidas: comparação entre os resultados obtidos em cada uma das quatro seqüências.

Dos trabalhos apresentados na Seção 2.3, o trabalho Pádua et al. (2003) é o único que faz a análise do fluxo de pedestres em ambientes abertos e utiliza uma metodologia similar à utilizada nesse trabalho e por isso será utilizado como referência para comparação dos resultados. O trabalho de Bartolini et al. (1994), apesar de também fazer uma análise espaço-temporal do fluxo óptico para a contagem de pedestres, aplica-a em um ambiente bastante restrito.

Analisando-se os resultados globais desse trabalho para a câmera Panasonic com o de Pádua et al. (2003), observa-se que as porcentagens de erro dos dois trabalhos diferem por um pequeno valor. Porém para a câmera Aiptek a margem de erro é maior. No entanto é importante destacar que o trabalho de Pádua et al. (2003) estima o fluxo unidirecional.

Comparando-se os resultados globais das duas câmeras através das Tabelas 5.1 e 5.2, observa-se um percentual de erro maior para a câmera Aiptek. Como a 
câmera Aiptek gera uma imagem de qualidade inferior, espera-se uma estimação do movimento menos precisa e a propagação desse resultado para as outras fases do algoritmo.

Fazendo-se a comparação entre as seqüências obtidas, para a câmera Panasonic, observa-se:

- para a seqüência 1 uma menor taxa erro. Essa seqüência é o caso mais simples do fluxo multidirecional, onde as pessoas caminham sozinhas paralelamente ao eixo $x$ ou $y$;

- para a seqüência 2, taxa de erro similar ao da seqüência 1. Nessa seqüência, as pessoas caminham aos pares, lado-a-lado;

- para a seqüência 3, taxas de erros mais elevadas. Nessa seqüência, os pedestres entram e saem da região monitorada com direção diagonais. Quando do processamento destas seqüências foi observado que para pequenas variações angulares ao redor de $90^{\circ}$, o resultado é similar ao das demais seqüências, enquanto que para variações angulares maiores a taxa de erro aumenta. Porém, esse limite angular não foi quantificado por não ser objetivo desse trabalho;

- para a seqüência 4, a taxa de erro encontra-se próxima ao da seqüência 1. Nessa seqüência, as pessoas caminham livremente. Considerando o resultado obtido para a seqüência 3, essa seqüência poderia apresentar uma taxa de erro mais elevada, se houvesse predominância do tipo de fluxo da seqüência 3.

Os índices de erros apresentados estão também relacionados com a posição da única câmera de vídeo utilizada e as posições das sub-áreas para a detecção e validação dos pedestres e de suas direções. Como a metodologia implementada tem como base a seqüência da ativação das sub-áreas adjacentes, os resultados ficam comprometidos quando um pedestre ativa duas sub-áreas simultaneamente, como ilustrado pela Figura 5.8. Os trabalhos descritas na Seção 2.3, utilizam, em sua maioria, câmeras colocadas na mesma posição utilizada aqui, porém, as regiões onde os pedestres são localizados e validados, ficam muito próximas ao eixo óptico da câmera, como ilustrado pela Figura 5.9, o que vem a reduzir os erros de contagem. Além disso esses trabalhos estão restritos à estimação do fluxo unidirecional.

Duas outras situações que ocasionaram erros foram identificadas:

- pedestres que caminham pela região monitorada, entrando nela, por exemplo, pela área 1 em direção à área 2, caminhando sobre a área 4. Nesta situação, 


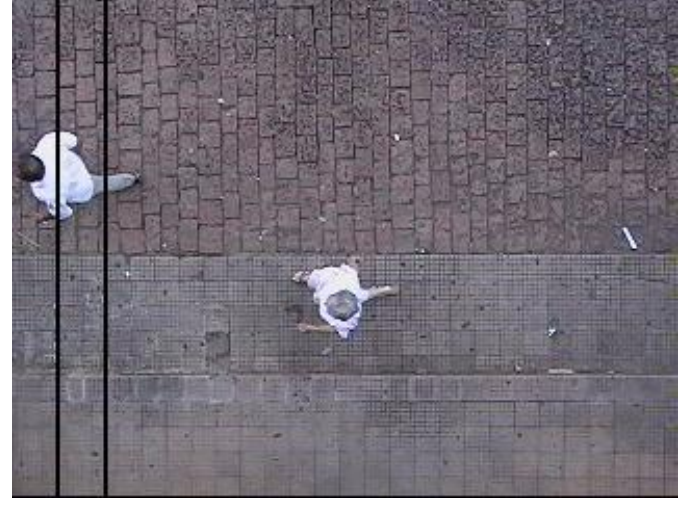

Figura 5.8: Pedestre saindo da região monitorada pela área 2. As linhas pretas verticais indicam os limites das sub-áreas 2-1 e 2-2.

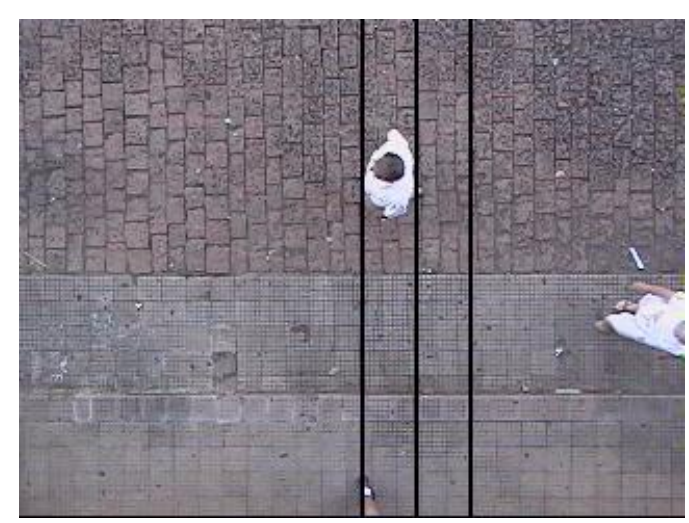

Figura 5.9: Mesmo pedestre visto na Figura 5.8, instantes antes, caminhando na região central.

apesar da compenente $\mathbf{u}$ do vetor $\mathbf{v}$, ser maior que a componente $\mathbf{r}$, a componente $\mathbf{r}$ não é nula, o que gera pulsos nas sub-áreas 4-1 e 4-2, contando pedestres entrando pela área 4. Na Figura 5.10 é ilustrada esta situação;

- pedestres entrando ou saindo da região monitorada pela intersecção, por exemplo, da área 1 e 4, conforme Figura 5.11. Nesta situação, duas área a são ativadas pelo mesmo pedestre.
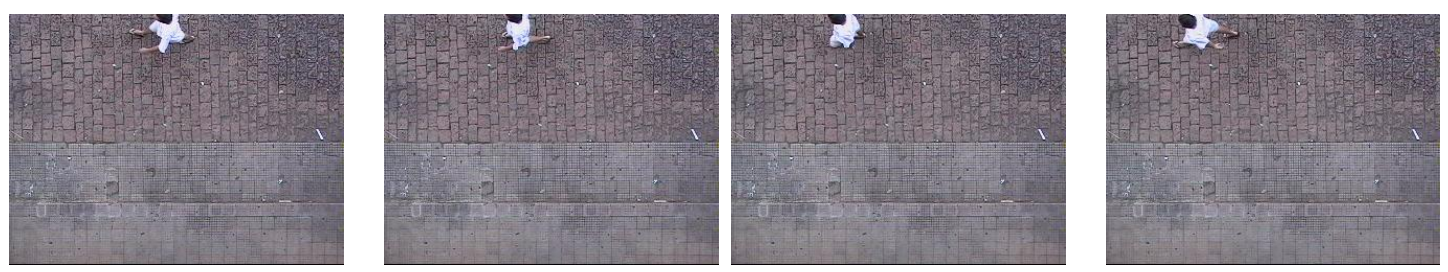

Figura 5.10: Pedestre caminhando da área 1 em direção a área 2, sobre a área 4.
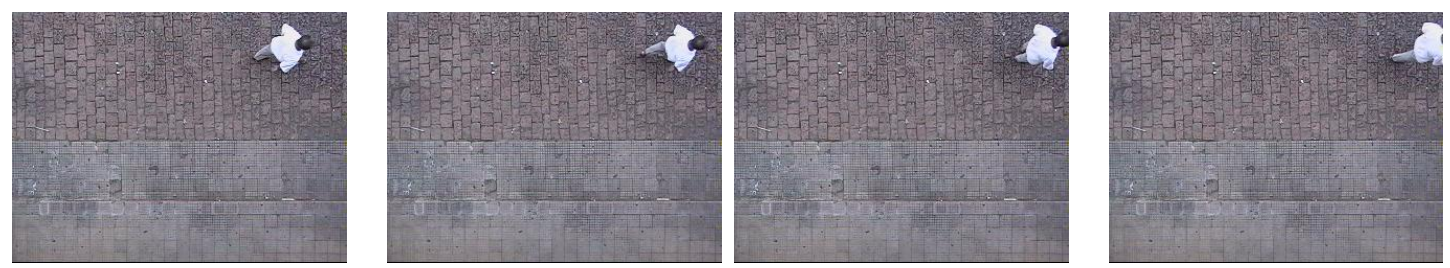

Figura 5.11: Pedestre saindo da região monitorada pela câmera de vídeo pela intersecção da área 1 e 4 . 


\section{Capítulo 6}

\section{Conclusões e sugestões para trabalhos futuros}

Nesse capítulo serão apresentadas as conclusões finais do trabalho e as sugestões para trabalhos futuros.

\subsection{Conclusões}

Neste trabalho foi proposta e implementada uma solução para a estimativa do fluxo multidirecional de pedestres em uma região aberta e não limitada, baseada exclusivamente na análise de seqüencias de imagens digitais obtidas por uma câmera de vídeo digital, tipo WEBCAM.

A estimativa deste fluxo foi realizada através da análise espaço-temporal dos campos de velocidade gerados pelo algoritmo de Lucas e Kanade (1981), obtendo-se dessa análise, a estimação do número de pedestres que cruzam a região monitorada pela câmera bem como suas direções.

Da análise dos resultados da Seção 5.4 conclui-se que:

- os erros obtidos são aceitáveis quando comparados com o trabalho de Pádua et al. (2003), principalmente considerando que a estimação feita no presente trabalho é realizada em uma região aberta e não restrita, onde o fluxo de pedestres é multidirecional, representando o caso mais complexo de fluxo de pedestres. Análise para esse tipo de fluxo não foi identificada na revisão bibliográfica;

- é possível a utilização de câmera digital, do tipo WEBCAM, mas os resultados obtidos com os dois modelo de câmeras, evidenciam que a qualidade da imagem 
gerada pela câmera influencia nesses resultados. A vantagem de se utilizar uma WEBCAM é a redução do custo financeiro, eliminando a necessidade da placa digitalizadora, que normalmente é de custo elevado. Outra vantagem é que facilita a implementação de um hardware dedicado;

- o sistema mostrou robustez quanto à distinção de pedestres caminhando muito próximos, lado-a-lado, conforme análise apresentada na Seção 5.3. Porém, a posição da câmera relativa às sub-áreas utilizadas, apresentou influência no resultado da contagem dos pedestres em todas as sequiências.

\subsubsection{Principais contribuições}

As principais contribuições deste trabalho são:

- a metodologia para a estimação do fluxo multidirecional de pedestres, uma vez que não foi identificado na revisão bibliográfica, trabalhos que analisem a estimação desse tipo de fluxo;

- a sua aplicação em espaços abertos e não restritos;

- a utilização de uma única câmera de vídeo digital de baixo custo.

\subsubsection{Limitações}

As limitações foram descritas na análise dos resultados, na Seção 5.4 e são as seguintes:

- limitação quanto ao ângulo de entrada/saída;

- pedestres caminhando nos limites da área monitorada;

- pedestres entrando/saíndo pela intersecção de duas áreas.

\subsection{Sugestões para trabalhos futuros}

Como sugestões para a melhoria da metodologia implementada, propõem-se:

- o estudo para a estimação dos movimentos diagonais acentuados;

- a alteração da posição das áreas monitoradas, conforme Figura 6.1, com o objetivo de minimizar o erro devido à ativação de duas áreas simultaneamente, causado pela distribuição das áreas. 
- implementação de um hardware dedicado, o que permitiria a instalação de um sistema automático de contagem de pedestres em locais de difícil acesso.

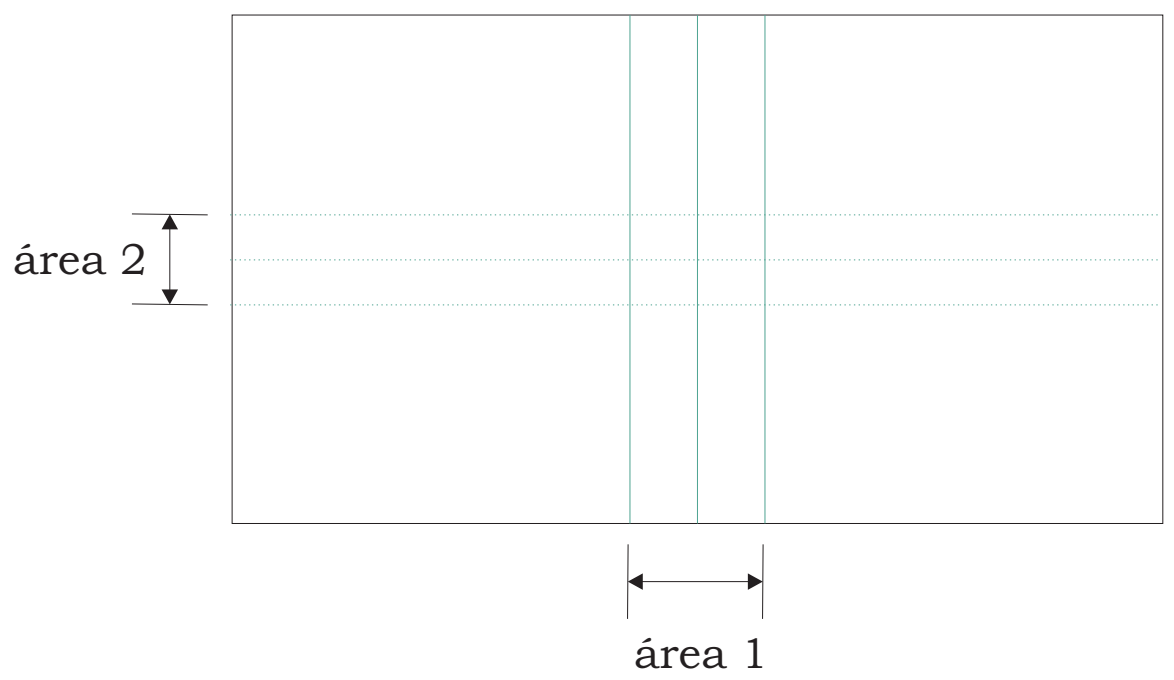

Figura 6.1: Posições sugeridas para as áreas utilizadas para contagem e estimação da direção dos pedestres. 


\section{Referências Bibliográficas}

Anandan, P. (1989). A computational framework and an algorithm for the measurement of visual motion. International Journal of Computer Vision, v.2, n.3, p.283-310. 17, 24, 26, 27, 28

Bab-Hadiashar, A. ; Suter, D. (1996). Robust optic flow estimation using least median of squares. In International Conference on Image Processing, p.513-516. Lausanne, Switzerland. 17

Barron, J. L.; Fleet, D. J. ; Beauchemin, S. S. (1994). Performance of optical flow techniques. International Journal of Computer Vision, v.12, n.1, p.43-77. 17, 26, 27

Bartolini, F.; Cappellini, V. ; Mecocci, A. (1994). Counting people getting in and out of a bus by real-time image-sequence processing. Image and Vision Computing, v.12, n.1, p.36-41. 1, 6, 50

Beauchemin, S. S. ; Barron, J. L. (1995). The computation of optical flow. Computing Surveys, v.27, n.3, p.433-467. 17

Beezley, E. A. (1999). Pedestrian traffic counting system. United States Patent number 5946368. 5

Beymer, D. (2000). Person counting using stereo. In Workshop on Human Motion, p.127-133. Austin, United States of America. 2, 9

Boykov, Y.; VeKsler, O. ; ZABih, R. (1998). A variable window approach to early vision. Transactions on Patter Analisys and Machine Intelligence, v.20, n.12, p.1283-1294. 9

Brox, T. (2002). Smoothing of matrix-valued data. , Thesis (Master) - University of Mannheim, Mannheim, Germany. 17

Camus, T. (1994). Real time optical flow. , Thesis (Master) - Brown University, Providence, United States of America. 15

Camus, T. (1997). Real-time quantized optical flow. Real-time Imaging 3, 71-86. 27,28

Camus, T. ; Bülthoff, H. H. (1995). Real-time optical flow extended in time. Technical report number 13, Max Planck Institut. 19

Corbett, D. R. (2000). Multiple object tracking in real-time. , Thesis (Master) The University of Queensland, Brisbane, Australia. 17 
Costa, V. M. S. (1998). Integração de comportamentos visuais para robótica móvel. , Dissertação (Mestrado) - Universidade Técnica de Lisboa, Lisboa, Portugal. 15

Del Bimbo, A. ; Nesi, P. (1993). Real-time optical flow estimation. In International Conference on Systems, Man and Cybernetics, v. 3, p.13-19. Le Touquet, France. 22

Del Bimbo, A.; Nesi, P. ; SAnz, J. L. C. (1995). Analysis of optical-flow constraints. Transactions on Image Processing v.4, n.4, p.460-469. 19

Del Bimbo, A. ; Santini, S. (1994). Motion analisys. , Florence, Italy, University of Florence. Technical Report. 19, 20

Diffrient, N.; Tilley, A. R. ; Harman, D. (1981). Humanscale 7/8/9. Cambridge: MIT Press. ix, 28, 29

Eikvil, L. ; Thune, M. (1998). Video and motion analysis - an overview. , Oslo, Norway, Norwegian Computing Center. Technical Report SAMBA/14/98. 17

Finley, F. R. ; Cody, K. A. (1970). Locomotive characteristics of urban pedestrian. Archives of Physical Medicine and Rehabilitation, n.51, p.423-426. 29, 30

Fitter, A. (1994). Counting people entering and leaving a zone. Patent Number:GB2278437, Application Number:GB19940006395 19940330 . 5

Fleet, D. J. ; Jepson, A. D. (1990). Computation of component image velocity from local phase information. International Journal of Computer Vision, v.5, n.1, p.77-104. 17, 26, 27, 28

Fleet, D. J. ; Jepson, A. D. (1992). Measurement of image velocity. Boston: Kluwer Academic. 26

FonsecA, I. S. A. (1998). Técnicas de visão aplicadas à navegação em robótica móvel. , Dissertação (Mestrado) - Universidade de Coimbra, Coimbra, Portugal. 25

Fruin, J. J. (1971). Pedestrian planning and design. Mobile: Elevator World, Incorporated. 28, 29

Galo, M.; Hasegawa, J. K. ; Tommaselli, A. M. G. (1999). Avaliação geométrica de câmaras de vídeo para uso em fotogrametria digital. In XIX Congresso Brasileiro de Cartografia. Recife, Brasil. 14

Galvin, B.; McCane, B.; Novins, K.; Mason, D. ; Mills, S. (1998). Recovering motion fields: an evaluation of eight optical flow algorithms. In Ninth British Machine Vision Conference, v. 1, p.195-204. Southampton, United Kingdom. 20, 26,27

GARCÉs, D. (1999). Body silhouette extration from video sequences., Thesis (Master) - École Polytechnique Fédérale de Lausanne, Lausanne, Switzerland. 16 
Garcia, R.; Palomo, C.; Leon, F. ; Lopez, I. (2000). People counting system by pressure images. Patent Number:EP0992949, Application Number:EP19990500166 19990917. 5

Gonzales, R. C. ; Woods, E. W. (1992). Processamento de imagens digitais. São Paulo: Edgard Blücher Ltda. 14

Goren, E. ; Garti, E. (1997). System and a method for counting people. United States Patent number 5656801. 5

Hashimoto, K.; Kawagushi, C.; Matsueda, S. ; Morinaka, K. (1998). People-counting system using multisensing application. Sensors and actuators A: Physical, v.66, n.1-3, p.50-55. 5

Hashimoto, K.; Morinaka, K.; Tsuruta, T. ; Yoshimke, N. (2000). High performance human information sensor. Sensors and actuators A: Physical, v.79, n.1, p.46-52. 5, 11

Hashimoto, K.; Yoshinomoto, M.; Matsueda, S.; Morinaka, K. ; YoshiIKE, N. (1997). Development of people-counting system with human-information sensor using multi-element pyroelectric infrared array detector. Sensors and actuators A: Physical, v.58, p.165-171. 5

HCM (2000). Pedestrian concepts, chapter 11 of the Highway Capacity Manual. Transportation Research Board - National Research Council. 29, 30

Heeger, D. J. (1988). Optical flow using spatio-temporal filters. International Journal of Computer Vision, v.1, n.4, p.279-302. 17, 25, 26, 28

Horn, B. K. P. ; Schunck, B. G. (1981). Determining optical flow. Artificial Intelligence, v.17, n.1-3, p.185-203. 17, 18, 20, 26, 27, 28

Hsieh, P.; Kuo, J. P. J.; Liu, S. K.; Mirmoeini, F.; Olyaei, A. ; Yousefi, P. (2002). Automatic passager counting system. , The University of British Columbia, Vancouver, Canada. Technical Report. 5

Jonson, H. (2001). Motion detection in sequences using optical flow. , Sweden, Lund University. Technical Report. 16

Kato, A. (1999). Number of people counting system. Patent Number:JP11219437, Application Number:JP9980019864 19980130 . 6

Ke-Okoro, S. ; Sandlund, B. (1984). Some effects of upward, downward, and level visual scanning and locomotion on distance estimation accurancy. Human Movement Studies, n.10, p.107-114. 29, 30

Kettnaker, V. ; Zabih, R. (1999). Counting people from multiple cameras. In International Conference on Multimidia Computing and Systems, v. 2, p.267-271. Florence, Italy. 9

Kim, J. W.; Chor, K. S.; Chor, B. D. ; Ko, S. J. (2002). Real-time vision-based people counting system for the security door. , Korea University, Seoul, Korea. Technical Report. 1, 2, 10 
Knoblauch, R. L.; Pietrucha, M. T. ; Nitzburg, M. (1996). Field studies of pedestrian walking speed and star-up time. Transportation Research Record, Pedestrian and Bicycle Research, n.1538, p.27-38. 29, 30

KuzINA, T. Y. (2000). Investigación e implementación de los algoritmos del campo de visón dinámica por computadora. , Tesis (Máster) - Univerdidad de las Américas, Puebla, México. vi, 21, 24, 25

Laplante, P. A. ; Stoyenko, A. D. (1996). Real-time imaging. Theory, techniques, and applications. New York: IEEE Press. 20, 22, 25, 26

Liu, H.; Hong, T.; Herman, M.; Camus, T. ; Chellappa, R. (1998). Accuracy vs. efficiency trade-offs in optical flow algorithms. Computer Vision and Image Understanding, v.72, p.271-286. 26, 27

Lucas, B. D. ; Kanade, T. (1981). An iterative image registration technique with an application to stereo vision. In Proceedings of Imaging Understanding Workshop, p.121-130. iv, v, 17, 22, 23, 26, 27, 28, 31, 32, 53

MARCEL, M. (2001). Active surface reconstrution from optical flow. , Thesis (Master) - McGill University, Montreal, Canada. 17

Masoud, O. ; Papanikolopoulos, N. P. (2001). A novel method for tracking and counting pedestrian in real-time using a single camera. Transactions on Vehicular Technology, v.50, n.5, p.1267-1278. 2, 10

NAGEL, H. H. (1983). Displacement vectors derived from second-order intensity variations in image sequences. Computer Vision, Graphics and Image Processing, v.21, n.1, p.85-117. 26, 27, 28

Nesi, P. (1994). Real-time motion estimation. , Florence, Italy, University of Florence. Technical Report. vi, 16, 17, 20, 21, 22, 24

Nesi, P.; Innocenti, F. ; Pezzati, P. (1998). Retimac: Real-time motion analysis chip. Transactions on Circuits and Systems, v.45, n.45, p.361-375. 8

Neufert, E. (1976). Arte de projetar em arquitetura.. Barcelona: Gustavo Gili. 29

Nitsuwat, S. (1998). Optical flow estimation. , Sidney, Australia, University of New South Wales. Technical Report. 17

NúÑez, F. V. (1996). Segmentación de Imágenes en grafos de contorno. Aplicación a la estimación de la profundidad y el movimiento relativo para un robot móvil autónomo. , Tesis (Doctorado) - Universidad de Vigo, Vigo, España. 13

Oliveira, I. N. S. (2003). Metodologia para detecção rápida de movimento em seqüências de imagens. , Tese (Doutorado) - Universidade de São Paulo, São Carlos, Brasil. 14, 15

Oliveira, I. N. S. ; Roda, V. O. (2001). Metodologia para detecção rápida do movimento em seqüências de imagens. In $V$ Simpósio Brasileiro de Automação Inteligente. Canela, Brasil. 15 
PÁduA, F. L. C. (2002). Contagem de pedestres em tempo real baseada em visão. , Universidade Federal de Minas Gerais, Belo Horizonte, Brasil. iv, v, 2, 11, 12, 14,28

Pádua, F. L. C.; Campos, M. F. M. ; Carceroni, R. L. (2003). Realtime pedestrin counting based on computer vision. In VI Simpósio Brasileiro de automação Inteligente. Bauru, Brasil. 1, 2, 50, 53

Proesmans, M.; Gool, L. V.; Pauwels, E. ; Oosterlinck, A. (1994). Determination of optical flow and its discontinuities using non-linear diffusion. In European Conference on Computer Vision, v. 2, 295-304. 27, 28

RitTneR, L. (2004). Identificação e transformação de valores aberrantes como medida de confiabilidade do método das diferenças para estimativa de fluxo óptico em seqüências de imagens. , Dissertação (Mestrado) - Universidade de Campinas, Campinas, Brasil. 14, 16, 25, 32

Roma, N. F. V. (2001). Processadores dedicados para estimação de movimento em seqüências de vídeo. , Dissertação (Mestrado) - Universidade Técnica de Lisboa, Lisboa, Portugal. vi, 14

Rossi, M. ; Bozzoli, A. (1994). Tracking and counting moving people. Image Processing, v.3, n.13-16, p.212-216. 7

Sacchi, C.; Gera, G.; Marcenaro, L. ; Regazzoni, C. S. (2000). Advanced image-processing tools for counting people in tourist site-monitoring applications. Signal Processing, n.81, p.1017-1040. 2

Sammarco, G. J. (1989). Basic biomechanics of the musculoskeletal system, cap. Biomechanics of the foot, p.163-181. Philadelphia: Lea \& Febiger. 29, 30, 31

Schofield, A. J.; Stonham, T. J. ; Menta, P. A. (1996). A system for counting people in video images using neural networks to identify the background scene. Pattern Recognition, v.29, n.8, p.1421-1428. 8

Schofield, A. J.; Stonham, T. J. ; Mehta, P. A. (1997). Automated people counting to aid lift control. Automation in Construction, n.6, p.437-445. 1, 8

Sexton, G.; Zhang, X.; Redpath, G. ; Greaves, D. (1995). Advances in automated pedestrian counting. Security and Detection, n.408, 106-110. 2, 6, 12

Shapira, A. (1997). Method for counting the number of people crossing an entry barrier. Patent Number:W09840719. 5

Singh, A. (1990). An estimation-theoretic framework for image-flow computation. In International Conference on Computer Vision, p.168-177. Osaka, Japan. 26, 27,28

Tekalp, A. M. (1995). Digital video processing. Upper Saddle River: Prentice Hall. vi, 15, 16

Terada, K.; Yoshida, D.; Oe, S. ; Yamaguchi, J. (1999). A counting method of the number de passing people using a stereo camera. Industrial Electronics Society, v.3, n.29, p.1318-1323. 9, 10 
Trucco, E. ; Verri, A. (1998). Introductory Techniques for 3-D Computer Vision. Upper Saddle River: Prentice Hall. 17

Uras, S.; Girosi, F.; Verri, A. ; Torre, V. (1989). A computational approach to motion perception. Biological Cybernetics, v.60, p.79-97. 26, 27, 28

Watkins, A. (2001). Counting apparatus. Patent Number:W00124118, Application Number:WO2000GB0358420000919 . 5

Waxman, A.; Wu, J. ; Bergholm, F. (1988). Convected activation profiles and the measurement of visual motion. In Computer Vision and Pattern Recognition, p.717-723. 26, 28

WegGer, J. (2000). Estimation of motion in image sequences. , Thesis (Master) - Göteborg University, Göteborg, Sweden. 17, 20

Yasutomi, S.; Mori, H. ; Kotani, S. (1996). Finding pedestrians by estimating temporal-frequency and spatial-period of the moving objects. Robotics and Autonomous Systems, v.17, n.1-2, p.25-34. 8

Zhang, X. ; Sexton, G. (1997). Automatic human head location for pedestrian counting. Image Processing and its Applications, n.443, p.535-540. 7 